\title{
ACCIONES, PLAZO DE INVERSIÓN Y MULTIFONDOS*
}

\section{Salvador Valdés}

Este estudio evalúa la recomendación que propone, a aquellos inversionistas cuyo plazo de inversión es largo (diez o más años), elevar la proporción invertida en acciones en razón que ese plazo es extenso. A su vez, se documenta la amplia difusión en Chile de esta recomendación.

Se señala que la revisión de la literatura muestra que la recomendación pro acciones basada en el plazo ha sido impulsada con distintos argumentos, muchos de los cuales han resultado falaces. Hacia fines de los años 90, no obstante, apareció una base más sólida para esa recomendación, a saber, que existe un autoseguro (natural hedge) en el retorno accionario, que modera el riesgo de las acciones sólo cuando el plazo de inversión es largo.

Campbell y Viceira (1999), entre otros, dieron el paso adicional de sostener que este autoseguro aconsejaría un aumento no modesto, sino que muy significativo, en la proporción accionaria. Sin embargo, otros académicos cuestionaron ese paso, indicando que un mayor plazo de inversión también eleva el riesgo por dos vías adicionales: 1) el error al predecir el premio por riesgo accionario del futuro crece con el plazo de inversión, y

Salvador Valdés Prieto. Doctor en Economía, Mit. Profesor titular de Economía de la Pontificia Universidad Católica de Chile. Este trabajo fue escrito cuando el autor era investigador del CEP.

* Agradezco los comentarios de Harald Beyer, Borja Larraín, Eduardo Walker, Ignacio Briones, Jorge Desormeaux M., Francisca Dussaillant, Klaus Schmidt-Hebbel y de los asistentes a un seminario en el Instituto de Economía de la PUC realizado en junio de 2009. Ellos no son responsables de lo afirmado en este estudio.

Estudios Públicos, 117 (verano 2010). 
2) el error de estimación de dicho premio desde los datos del pasado crece con el plazo por existir menos datos independientes entre sí. La cuestión es si estos dos nuevos factores compensan al autoseguro accionario. El estudio de Pastor y Stambaugh (2009) encuentra que lo compensan de sobra, sugiriendo que un mayor plazo de inversión llevaría a reducir la fracción en acciones.

Este trabajo concluye que si bien no es recomendable invertir sólo en bonos indexados, tampoco puede recomendarse invertir una alta proporción en acciones sólo en razón de que el plazo de inversión sea largo.

Entre las lecciones para efectos de política pública, el estudio destaca que la motivación del Estado para obligar al afiliado a ahorrar, que es asegurar un cierto nivel de vida en la vejez, no es congruente con permitirle apostar sus ahorros obligatorios en carteras de alto riesgo en el largo plazo, como aquellas con 78\% en acciones, como ha sido el fondo A desde 2004.

Palabras clave: inversiones; premio por riesgo accionario; razón dividendo a precio; riesgo muestral; pensiones.

Clasificación JEL: G11, G23, H55.

\section{Introducción}

ـ a crisis financiera de 2008-2009 es una ocasión propicia para revisar la evidencia de la influencia del plazo de la inversión en el riesgo de las acciones, en comparación con el riesgo de la renta fija de largo plazo indexada al IPC.

Las acciones son una inversión adecuada para cualquier inversionista, y también para los fondos de pensiones, porque el premio por riesgo promedio es positivo. Sin embargo, la cuestión que aborda este estudio es otra: ¿varía el premio por riesgo de manera de justificar elevar la proporción en acciones sólo porque el plazo de inversión es largo? La respuesta es no, porque la magnitud de dicho premio es igual por unidad de tiempo, cualquiera sea el plazo de inversión. En consecuencia, la fracción de la cartera a mantener en acciones sólo puede depender del plazo de inversión por la vía de la magnitud del riesgo, no por la vía de la magnitud del premio por riesgo promedio. 
Respecto al riesgo se ha afirmado lo siguiente:

En el período de mayor baja del mercado accionario el Fondo A de las AFP llegó a caer hasta un $45 \%$ a octubre de 2008 , medido en 12 meses. Esto motivó ácidas críticas hacia el sistema... Transcurrido un poco más de un año, esa baja se ha recuperado con el aumento experimentado por el mercado bursátil. Las cifras de cierre del 2009 muestran que el Fondo A tuvo un poco más de $40 \%$ de rentabilidad real. (Editorial diario La Tercera, 4 de enero 2010.) ${ }^{1}$

...en períodos largos [un conjunto diversificado de acciones] tiende a exhibir un mejor rendimiento que los instrumentos de renta fija, y si bien están sometidos a mayor volatilidad, el mayor plazo permite recuperarse de los ciclos adversos. (Editorial diario El Mercurio, 30 de enero 2010.)

El argumento de la recuperación casi segura es conocido en la literatura como "diversificación en el tiempo". Si la recuperación fuera casi segura, la alta variabilidad mensual o anual de los retornos accionarios (la "volatilidad") no pasaría de ser un mero "susto" sin importancia: el valor final de la inversión accionaria sería muy seguro (poco riesgoso) porque los ciclos adversos serían recuperados en plazos largos como los mencionados ${ }^{2}$. Es decir, la volatilidad sería un distractor, que despista a los asustadizos y desinformados, pero no un riesgo real para quienes pueden (o deben) esperar diez o más años y por tanto sólo se interesan en el valor final de su inversión. La fortaleza de carácter o convicción necesaria para perseverar durante una eventual larga fase adversa del ciclo, hasta que la recuperación ocurra, es un tema separado, que no abordamos aquí.

La creencia en que un proceso cíclico siempre recuperaría las pérdidas, implica que el valor final de una inversión accionaria superaría siempre al valor final de una cartera de renta fija, para plazos suficientemente largos. Si ello fuera así, convendría invertir en acciones la mayor proporción posible cualquiera fuera la aversión al riesgo del inversionista, siempre que el plazo fuera largo. El efecto potencial

${ }^{1}$ Aparte de confundir el retorno ex post con el conjunto de retornos posibles ex ante, que es el único pertinente, ese texto comete un error aritmético: un alza de 45\% no recupera una pérdida de 45\%, porque la base de comparación varía. En efecto, 100x(1$0,45) \times(1+0,45)=0,798$, de modo que subsiste una pérdida de 20,2\% en ese ejemplo.

2 Para abreviar y evitar reiteración, omitimos la mención de que se trata de retornos relativos a los bonos de largo plazo indexados al IPC. 
de esta tesis sobre la elección de multifondo en un sistema de pensiones de capitalización es importante. Veremos que esa tesis ha sido rechazada, en favor de otra que indica que las acciones son más riesgosas que la renta fija, a todos los plazos.

La opinión citada se originó en la industria financiera de los países avanzados a inicios del siglo pasado, y aún prevalece en los sectores menos informados de esos países. La revisión acometida en este estudio muestra que esta creencia fue resucitada en 1994 por J. Siegel sobre la base de argumentos empírico-históricos para Estados Unidos. Sin embargo, la interpretación de Siegel fue sólidamente disputada en los círculos académicos de esos mismos países, con datos y teoría. Incluso, veremos cómo el propio J. Siegel la descartó para el caso donde la inversión alternativa consiste de bonos largos indexados al IPC, que es el caso relevante en el mundo hoy. La evidencia histórica originada en treinta países distintos de Estados Unidos, elaborada por Dimson, Marsh y Staunton (2002) y por Jorion (2003), confirmó el rechazo empírico al argumento original de Siegel. Así, el grueso de los profesionales de la industria financiera internacional rechaza la opinión citada. Sin embargo, en Chile estos contraargumentos son poco conocidos y el argumento original continúa siendo promovido por algunos.

Hace diez años, el debate mundial se trasladó a un estadio superior. Se empezó a debatir una rehabilitación parcial del consejo proaccionario, sobre la base de que el retorno accionario exhibe un autoseguro (natural hedge) parcial. Siguiendo el lenguaje de la recuperación cíclica de las pérdidas accionarias, la magnitud del autoseguro sería suficiente para que el valor final de la inversión accionaria goce de una variabilidad reducida. Con todo, el valor final de la inversión accionaria quedaría por debajo del valor final de una cartera de renta fija en una fracción importante de casos, aún para plazos largos. Esta rehabilitación fue liderada por Campbell y Viceira (1999) y defendida eficazmente en su aspecto estadístico por Cochrane (2008).

Si el autoseguro accionario actuara solo, se deduciría la siguiente recomendación para aquellos inversionistas cuyo horizonte de inversión es largo, digamos sobre diez años: elevar la proporción de los ahorros invertida en acciones, a un nivel mayor que el que hubiera elegido en caso de creer que el riesgo está dado por la volatilidad mensual o anual. Esta recomendación supone que se mantiene constante la aversión al 
riesgo, y que se mantiene constante el exceso de retorno de las acciones por sobre la renta fija que promedia los diversos escenarios posibles. Contrariamente al argumento original de Siegel, el autoseguro accionario sólo recomienda elevar en forma finita la proporción de los ahorros invertida en acciones, pues la aversión al riesgo juega su rol.

Según Campbell y Viceira (2002, cap. 7) y según Viceira (2009), su recomendación debería ser aplicada a todos los afiliados activos e incluso a una buena parte de los pensionados, pues la mayoría de ellos vivirá más de diez años en promedio. En Chile, la esperanza de vida de una afiliada de 60 años es 26,12 años, y la esperanza de vida de un afiliado de 65 años es 18,24 años ${ }^{3}$. Como la fase de retiro es larga, el pensionado en retiro programado que elija un multifondo con más acciones también se beneficiaría del autoseguro accionario.

Sin embargo, durante la última década académicos igualmente connotados han refutado esa recomendación, como ocurre en Barberis (2000) y Pastor y Stambaugh (2009).

La escasez de observaciones y la predicción con error son fuentes adicionales de incertidumbre para el inversionista. $\mathrm{Al}$ aumentar el plazo de inversión, el riesgo del valor final aumenta por varias consideraciones de este tipo. Primero, cuando el promedio futuro del retorno accionario varía en el tiempo, ese promedio futuro se predice con error bajo cualquier sistema predictivo ${ }^{4}$. Esto es válido incluso para el promedio de retornos futuros a un año plazo estimado hoy. Segundo, ese error se propaga a todos los demás aspectos de la predicción. En particular, cuando aumenta el horizonte de predicción, el error se acumula por más años, y como existe persistencia, se potencia. Tercero, es sabido hace tiempo que para horizontes de inversión más largos disponemos de menos observaciones históricas independientes sobre los retornos acumulados, es decir hay menos observaciones no superpuestas en el tiempo. Esta fuente de incertidumbre aumenta al crecer el plazo de inversión.

3 Fuente: https://www.svs.cl/sitio/admin/Archivos/com_20070831-01.PDF. El plazo hasta la fecha normal del retiro (60 mujer /65 hombre) es muy inferior al horizonte de vida. Para decidir el porcentaje a invertir en acciones, el horizonte que importa es el de vida, a menos que se obligue a los afiliados a comprar una renta vitalicia fija al iniciar su retiro, y se prohíban el retiro programado y la renta vitalicia variable.

${ }^{4}$ La variación en el tiempo del retorno esperado futuro es requisito para que exista autoseguro accionario. 
La presencia de estos factores no desmiente la existencia del autoseguro accionario, pero al ir en la dirección opuesta podrían hacer que el riesgo de invertir en acciones crezca al aumentar el plazo de la inversión. En efecto, al combinar el efecto de estas consideraciones con 206 años de datos para Estados Unidos, Pastor y Stambaugh (2009) demuestran que la varianza anualizada del retorno accionario a treinta años plazo es entre ¡20 y 50\% mayor! que la varianza del retorno de un solo año. A diez años plazo es $8 \%$ mayor.

Según esos autores, existe más incertidumbre por unidad de tiempo para quien invierte a plazos largos que para quien invierte a corto plazo. Reconociendo además que una cartera de bonos soberanos de largo plazo indexados al IPC tiene un riesgo de largo plazo muy inferior a las acciones, se obtiene la recomendación opuesta: conviene reducir la proporción de la riqueza invertida en acciones hasta un nivel inferior al que se hubiera elegido en caso de creer que el riesgo está dado por la volatilidad mensual o anual, aunque sin bajarla a cero tampoco. Esta conclusión ha sido reforzada por la crisis financiera de 2008-2009 y cuenta con muchos defensores en los Estados Unidos, como reporta Time el 15 de junio de $2009^{5}$.

Este estudio no recomienda invertir sólo en bonos indexados. Sólo desvirtúa la creencia de que un plazo largo de inversión justifica elevar la fracción accionaria.

Una consecuencia es que está equivocada la tesis de que los afiliados con horizonte largo — casi todos, pues hasta los hombres de 65 años tienen una esperanza de vida de 18,24 años- deberían preferir el multifondo con mayor proporción invertida en acciones. Ella es incorrecta para personas cuya aversión al riesgo presenta niveles moderados y altos, como muchos de esos hombres de 65 años. La difusión en Chile de la tesis pro accionaria, además de varias falacias más antiguas asociadas al plazo de inversión, documentada en las secciones 2.4, 3 y en el Anexo, arriesga la seguridad de las pensiones de capitalización sin una compensación suficiente en el nivel promedio de las pensiones.

Conviene mencionar aquí brevemente otros argumentos. Si bien la aversión al riesgo tiende a ser menor para los más jóvenes, la magnitud de la disminución es leve, tanto así que para muchos la mejor

${ }^{5}$ Ver http://www.time.com/time/magazine/article/0,9171,1902843-3,00.html 
cartera a los 35 años difiere poco de la mejor cartera a los 65 (Campbell y Viceira 2002, Cuadro 7.4). Tampoco se puede justificar un mayor nivel promedio para la fracción accionaria a lo largo de la vida aduciendo que la estrategia de reducir la fracción accionaria al avanzar en edad optimiza el riesgo total, pues para muchos el riesgo total se optimiza con la estrategia opuesta, esto es: iniciar la vida laboral con una fracción accionaria nula o baja y luego aumentarla al avanzar en edad (Benzoni et al., 2007).

Entre las lecciones obtenidas en este estudio para efectos de política pública, destaca la siguiente: la motivación del Estado para obligar al afiliado a ahorrar, que es asegurar un cierto nivel de vida en la vejez, no es congruente con permitirle apostar sus ahorros obligatorios en carteras de alto riesgo de largo plazo, como aquellas con $78 \%$ en acciones, como ha sido el actual fondo A desde 2004.

\section{Antecedentes de la teoría económica}

Cuando una persona posee riqueza financiera debe decidir en qué invertirla. La principal decisión de inversión es cómo distribuir esa riqueza entre renta variable (“acciones”) y renta fija (“bonos”) ${ }^{6}$. Uno de los elementos que inciden en esta decisión, según la teoría económica, es el "premio por riesgo accionario" $\left(P P R A_{t}\right)$.

El $P P R A_{t}$ se define como el promedio de la diferencia entre el valor final de la inversión en acciones y el valor final de la inversión en bonos, entre todos los posibles escenarios futuros. Este promedio es condicional a la información disponible al momento de elegir, en la fecha $t^{7}$ Notemos que sólo interesan los retornos acumulados.

\footnotetext{
${ }^{6}$ Se entiende que el bloque de inversión en "acciones" está atomizado entre miles de acciones individuales. A ese bloque se suma la parte del ingreso laboral (salarios + honorarios) cuyo crecimiento está altamente correlacionado con el retorno accionario. Empíricamente, esa correlación es alta para el ingreso laboral a recibir en un plazo lejano, por ejemplo a más de diez años. También se entiende que el bloque invertido en renta fija está atomizado entre miles de instrumentos de renta fija, en UF, de distintos países, a distintos plazos de vencimiento. A este bloque también se suma la parte del ingreso laboral "seguro", que está altamente correlacionado con el retorno de la renta fija. Empíricamente, esa correlación es alta con el ingreso laboral recibido a plazos "cercanos", por ejemplo a menos de cinco años (Benzoni et al., 2007).

${ }^{7}$ Técnicamente, ésta es la esperanza matemática condicional a la información disponible en $t$.
} 
El PPRA $A_{t}$ no es observable directamente, porque es una percepción subjetiva de los inversionistas respecto del futuro. Para enfatizar esto definimos la diferencia efectivamente observada entre estos valo-

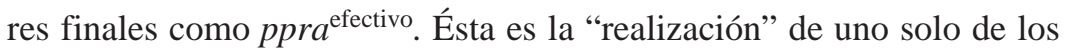
miles de escenarios posibles considerados en el promedio que conduce a PPRA. Por definición:

$P P R A_{t}=$ Promedio (posibles escenarios) $\left[p{ }^{\text {efectivo }}\right]$ percibidos al momento de invertir.

\subsection{Efectos de la optimización por parte de los inversionistas sobre el PPRA}

Los inversionistas optimizan su cartera. Por ejemplo, si perciben que un tipo de inversión vence a otro en todas las situaciones posibles, entonces no invertirían en este último. A nivel agregado, ello haría bajar el precio de esa inversión o activo. Sin embargo, ese menor precio eleva la rentabilidad de invertir en ese activo. El precio del activo vencido baja hasta que deja de ser vencido en algunas situaciones. Un importante resultado de la teoría económica es que:

$P P R A_{t}>0$

Es decir, el $P P R A_{t}$ es positivo. En efecto, si las acciones presentan un atributo indeseable, como ser más riesgosas en su resultado, la única motivación para preferir acciones por sobre la renta fija es que las primeras tengan otro atributo positivo, que compense al inversionista por el atributo indeseable. Ese atributo positivo es que en el promedio de todos los escenarios posibles las acciones obtengan un mayor valor final.

Si no fuera así, los inversionistas preferirían invertir en renta fija toda su riqueza, y no invertirían en acciones. A nivel agregado, ello haría bajar el precio de las acciones, y eso subiría su rentabilidad promedio percibida. Esto continuaría hasta que se cumpla la ecuación (2). La predicción de que el $P P R A_{t}$ es positivo cuenta con un enorme respaldo empírico, en diversos países y períodos. 
Un segundo resultado clave de la teoría económica es que las diferencias entre el valor final de la inversión en acciones y el valor final de la inversión en bonos deben ser necesariamente negativas en por lo menos un escenario posible. Es decir:

Mín (posibles escenarios) $\left[p_{p r a}{ }^{\text {efectivo }}\right]_{\text {percibidos al momento de invertir }}<0$

En efecto, si se percibiera que en ningún escenario esta diferencia es negativa, entonces las acciones rentarían más que los bonos en todos los escenarios posibles, con total seguridad. En ese caso, los inversionistas preferirían invertir en acciones toda su riqueza, y no invertirían en bonos, porque estos últimos serían menos rentables con toda seguridad ${ }^{8}$.

A nivel agregado ello haría bajar el precio de los bonos y subir su rentabilidad percibida, hasta que se cumpla la ecuación (3).

Los resultados (2) y (3) son complementarios. En efecto, ¿por qué dar un "premio" a quienes inviertan en acciones, si las acciones nunca rinden menos que los bonos? Si el precio de las acciones entregara un valor final que en todos los escenarios supere al valor final entregado por los bonos, ¿por qué recibirían los inversionistas en acciones un "premio", si nunca pierden? Sólo hay verdadero riesgo cuando existe alguna probabilidad de ser vencido por la inversión alternativa. La magnitud del riesgo depende de la magnitud de la derrota y de su probabilidad.

De pasada, esto nos advierte por qué es incorrecto medir el riesgo con la volatilidad o varianza, excepto para ciertas distribuciones especiales como la lognormal. En otras distribuciones es posible que una de ellas venza siempre a otra, pero que la vencida tenga retornos más estables, es decir menor volatilidad o varianza.

Otra forma de resumir esto es que los activos más riesgosos deben tener mayor rentabilidad en promedio. Que esto ocurra "en promedio" y no en todos los casos es precisamente lo que da cuenta del riesgo que existe.

\footnotetext{
${ }^{8}$ Los bonos estarían dominados estocásticamente en el sentido de primer
} orden. 


\subsection{Ciclos en los precios y diversificación en el tiempo}

La evidencia histórica muestra que los precios de las acciones presentan "ciclos", en el sentido de que después de un retorno alto normalmente sigue un retorno bajo. Sin embargo, es esencial distinguir entre dos tipos de ciclo:

a) ciclo de precios determinístico, donde el mero transcurso del tiempo o de otras variables observables permite predecir cuándo variará un precio;

b) ciclo de precios aleatorio, donde no se sabe cuándo empezarán los retornos bajos, ni cuándo terminarán los retornos altos. En un ciclo aleatorio, las variaciones de precio son impredecibles.

Adoptemos por un momento la hipótesis de que los retornos accionarios son "predecibles", sea utilizando datos de los precios de acciones en el pasado, o del tiempo transcurrido. Combinando con la hipótesis de que existe un ciclo en los retornos, se deduce que los datos del pasado ayudan a predecir cuándo ocurrirá la recuperación de las pérdidas. Otro efecto de la recuperación es que, con seguridad, los retornos bajos (negativos) son compensados con retornos altos. En ese caso, un aumento de horizonte de inversión permitiría destruir (o diversificar) el riesgo, pues daría más tiempo a que ocurra dicha compensación. Esa compensación se mostraría como una correlación temporal negativa entre los retornos accionarios a lo largo del tiempo. Ésta es la “diversificación en el tiempo", que es el argumento más antiguo que vincula preferir las acciones cuando se trata de una inversión en un horizonte largo.

La evidencia empírica rechaza categóricamente estas dos hipótesis: en efecto, los precios de las acciones son muy poco predecibles utilizando datos de los precios de acciones en el pasado, o del tiempo transcurrido; y la correlación temporal de los retornos es cercana a cero (ver Campbell y Viceira 2002, ecuación para acciones en cap. 4).

Existen buenos motivos para ello: si fuera posible predecir con precisión cuándo empezará a subir el precio de las acciones, entonces sería muy rentable usar esa información para ganar dinero sin riesgo: se pide crédito y se destinan esos recursos a comprar acciones en la fase barata, para venderlas cuando el ciclo se revierta, aprovechando que la recuperación será segura. Pero si fuera posible predecir con precisión cuándo subirá el precio de las acciones, el intento general de 
comprar acciones y la ausencia de personas dispuestas a vender acciones aumentaría su precio de inmediato. ¿Por qué habría alguien dispuesto a vender al precio "bajo", que no toma en cuenta esa información? Casi no habría transacciones hasta que el balance de riesgos sea incierto nuevamente.

Por esto, los únicos ciclos admisibles para los precios de activos que se transan a bajo costo -incluyendo acciones- son los ciclos aleatorios. En ellos la predicción tiene baja precisión. Esta ausencia de precisión implica que no hay seguridad alguna de que las ganancias y pérdidas se compensen, ni siquiera en el largo plazo, aunque mirando el pasado parezca posible adivinar "ciclos".

\subsection{La elección óptima de cartera}

Según la teoría económica, el $P P R A_{t}$ no es el único elemento que incide en la decisión de inversión. Un segundo elemento que incide es el nivel de riesgo de las inversiones accionarias, en relación con el riesgo de las inversiones en renta fija. El riesgo puede medirse de varias maneras: según dominancia estocástica en el caso general, o con la varianza para distribuciones lognormales, o con rangos de variación.

Un tercer elemento en la decisión de inversión es la preferencia del inversionista, en especial el grado de su aversión al riesgo de inversión (o su inverso, que es el grado de tolerancia al riesgo de inversión).

Para ilustrar esto, la ecuación (4) reporta la fórmula para la fracción óptima de la riqueza que conviene destinar a acciones, para un caso simple ampliamente estudiado en la literatura9 ${ }^{9}$. El caso es "simple" porque supone que el grado de aversión al riesgo de inversión es independiente de la riqueza del inversionista. También supone que no se permite rebalancear la cartera al interior del horizonte de inversión, que no hay aportes ni retiros de fondos al interior de ese horizonte, que los

${ }^{9}$ Se obtiene de la condición de primer orden para maximizar la utilidad esperada del inversionista en el caso simple. Existen fórmulas análogas para cada caso menos simple. Fuentes: Merton, R. C. (1971); Campbell y Viceira (2002), ecuación (2.27), p. 30. Este método para obtener (4) es superior al de la frontera de Markowitz, por dos razones: (1) esa frontera no entrega una solución analítica para preferencias razonables de los inversionistas (la utilidad cuadrática no es razonable); y (2) esa frontera sólo tiene validez si la distribución de retornos absolutos — no sus logaritmos- es gaussiana, lo cual es imposible porque daría probabilidad positiva a tasas de retorno inferiores a $-100 \%$. 
números $P P R A_{t}$ y $\operatorname{VarACC}_{t}$ son conocidos con total exactitud, que no hay incertidumbre respecto del modelo y las distribuciones, y que la distribución del logaritmo de la rentabilidad de las acciones tiene una distribución "normal” o gaussiana.

En este caso simple, la maximización de la utilidad esperada de un inversionista racional, respecto del porcentaje de la cartera destinado a acciones, entrega la siguiente respuesta:

$$
\alpha_{t}^{*}=\alpha_{M V}+P P R A_{t} \times\left(\frac{1}{\text { Riesgo ACC }}\right) \times\left(\frac{1}{\gamma}\right) \mathrm{y}
$$

Riesgo $A C C_{t}=$ VarACC $_{t}$ en el caso gaussiano,

donde:

$\alpha_{t}^{*}=$ fracción de la riqueza que se recomienda asignar a acciones, al decidir en $t$.

$\alpha_{M V}=$ fracción invertida en acciones de la cartera de mínima varianza. Ésta es una cartera específica, que permite tomar en cuenta que los bonos sufren algún riesgo de crédito o de reinversión. Si los bonos son seguros, no hay tales riesgos y $\alpha_{M V}=0$.

$P P R A_{t}=$ diferencia entre el valor final de la inversión en acciones y el valor final de la inversión en la cartera de mínima varianza, promediada entre todos los posibles escenarios futuros, condicional a la información disponible en $t$.

RiesgoACC $_{t}=$ índice del riesgo subyacente intrínseco, para la diferencia de rentabilidad efectiva entre las acciones y la renta fija. Se mide con algún indicador de la variabilidad de la diferencia entre la rentabilidad accionaria y la rentabilidad de la cartera de mínima varianza, en los distintos escenarios posibles, condicional a la información disponible en $t^{10}$.

$\gamma=$ coeficiente de "aversión relativa al riesgo". El inverso $(1 / \gamma)$ se conoce como el "coeficiente de tolerancia al riesgo". Mide las preferencias del inversionista ${ }^{11}$.

${ }^{10}$ El valor de RiesgoACC $C_{t}$ tampoco es observable directamente, porque es una expectativa subjetiva de los inversionistas. Debe ser medido, y ello ocurre con error en muchos casos.

${ }^{11}$ La tradición en finanzas, respaldada por estudios empíricos y experimentos, es que el coeficiente $\gamma$ varía entre 5 y 10, sin perjuicio de que existan casos más extremos. 
$\operatorname{VarACC}_{t}=$ varianza. Éste es un indicador de riesgo que promedia entre los distintos escenarios posibles las desviaciones alrededor del promedio de las diferencias entre los logaritmos de rentabilidad, elevando dichas diferencias al cuadrado. Al elevarlas al cuadrado da más importancia a las desviaciones de mayor magnitud. La varianza es igual a RiesgoACC ${ }_{t}$ cuando el logaritmo de la rentabilidad de las acciones tiene una distribución "normal” o gaussiana ${ }^{12}$.

El óptimo en (4) también tiene sentido intuitivo: si el PPRA aumenta, dejando todo lo demás constante, conviene elevar la fracción de la cartera invertida en acciones. Si el riesgo accionario subyacente (RiesgoACC ${ }_{t}$ ) aumenta, dejando todo lo demás constante, ocurre lo contrario: conviene reducir la fracción de la cartera invertida en acciones. Por último, si aumenta la aversión al riesgo $(\gamma)$ del inversionista, con todo lo demás constante, entonces conviene reducir la fracción de la cartera invertida en acciones.

La lección más importante de la fórmula (4) es que para decidir qué fracción de la riqueza destinar a acciones, no basta con conocer $P P R A$, aun suponiendo que PPRA esté medido con exactitud. También es necesario conocer el riesgo intrínseco RiesgoACC.

Otra lección importante de (4) es que nunca es óptimo reducir a cero el porcentaje invertido en acciones. En efecto, en la medida en que se cumpla (2), la ecuación (4) revela que $\alpha^{*}$ siempre será superior a $\alpha_{M V}$. Esto implica que un porcentaje positivo en acciones en un sistema previsional de capitalización siempre beneficia al afiliado.

¿Qué incidencia tiene el horizonte de inversión sobre $\alpha^{*}$, la fracción de la cartera que debería estar invertida en acciones? Un aumento en el horizonte de inversión puede afectar a cada uno de los factores indicados en (4), y en distinta medida. Eso no es todo: el horizonte también puede afectar a varios de los supuestos simplificadores que se usaron para obtener (4).

Las preferencias para $\gamma=1$ son demasiado tolerantes al riesgo para ser realistas, pues en ese caso el inversionista se interesa solamente en el promedio del retorno logarítmico de la cartera de inversión, y le resulta irrelevante la variabilidad de ese retorno (Campbell y Viceira, 2002, ec. 2.18, p. 26-27 y 36).

${ }^{12}$ La Varianza no puede ser calculada (es infinita) cuando la distribución de retornos tiene colas más gruesas que la distribución gaussiana o "normal”. En ese caso es conveniente ajustar una distribución de la familia "estable”. Se encuentra empíricamente que los retornos accionarios tienen colas más gruesas que la distribución gaussiana (Ortobelli, Huber y Schwartz, 2002). 


\subsection{Razonamientos incompletos asociados al PPRA}

Un error habitual es proponer como medida de riesgo la probabilidad de que las acciones venzan a la renta fija.

La probabilidad es una medida incompleta del riesgo porque omite dos aspectos que son importantes, según la teoría de la utilidad esperada:

a) La profundidad de la pérdida en caso de perder (y el nivel de la ganancia promedio en caso de ganar). Manteniendo constante la probabilidad de que las acciones sean vencidas por la renta fija, es peor aquel caso donde la pérdida promedio es más profunda, que aquél donde la pérdida promedio es más modesta. Esta distinción es omitida cuando se usa una probabilidad como medida de riesgo ${ }^{13}$.

b) La variabilidad en la profundidad de la pérdida en caso de perder (y la variabilidad de la ganancia promedio en caso de ganar). Manteniendo fijas la probabilidad de ganar y dejando también fijas la ganancia esperada en caso de ganar y la pérdida esperada en caso de perder, es peor el caso donde la pérdida es más variable, que aquél donde la pérdida promedio es menos variable (ídem con las ganan(ias) $)^{14}$. El aspecto más insidioso de usar una probabilidad aislada como medida de riesgo es omitir la magnitud de VarAcc, que controla la segunda distinción.

A medida que aumenta el plazo de la inversión, estos ítems varían de la siguiente forma:

1. Aumenta la probabilidad de que venzan las acciones, tendiendo a $100 \%$ (uno).

2. La magnitud media de la diferencia negativa aumenta sin límite. A medida que aumenta el horizonte, es más probable que toque una recesión más profunda.

3. La magnitud media de la diferencia positiva también aumenta, sin límite. A medida que aumenta el horizonte, es más probable que toque un auge grande.

\footnotetext{
${ }^{13}$ Por definición, $P P R A=\operatorname{Prob}\left(V F_{\text {Acciones }}>V F_{\text {Bonos }}\right) \times$ Promedio(Valor Final $/$

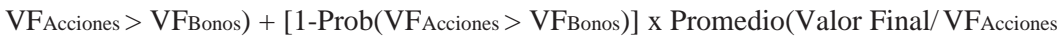
$<$ VFBonos). Esto demuestra que si bien la probabilidad de que las acciones venzan a los bonos afecta al $P P R A$, ella no es el único determinante, pues también influyen las profundidades promedio de las pérdidas y las ganancias.

${ }^{14}$ De modo análogo, se define que $\operatorname{VarAcc}=\operatorname{Prob}\left(V_{F_{\text {Acciones }}}>V F_{\text {Bonos }}\right) \mathrm{x}$ Varianza (Valor Final/VFAcciones $>$ VFBonos) + [1-Prob(VFAcciones $>$ VFBonos)] x Varianza (Valor Final/ VFAcciones < VFBonos). Si bien la probabildiad también influye aquí, de nuevo es insuficiente para determinar VarAcc.
} 
Combinando estas tres tendencias, el PPRA acumulado hasta el término del plazo, aumenta sin límite cuando crece el plazo de inversión. Sin embargo, detener aquí el análisis sería incompleto, porque también es crucial:

4. La magnitud de la variabilidad del valor final aumenta, sin límite.

Si al aumentar el plazo de inversión aumenta tanto el $P P R A$ acumulado como la variabilidad del valor final VarAcc, la proporción de la riqueza a invertir en acciones variará dependiendo de cuál factor crezca más, en el caso donde el grado de tolerancia al riesgo permanece constante a todos los horizontes. Si todos crecieran en igual proporción, como ocurriría en el caso sin autoseguro accionario, y la aversión al riesgo permaneciera constante, entonces la proporción óptima invertida en acciones no cambiaría al variar el plazo (Samuelson, 1979).

\subsection{Evidencia empírica sobre el tamaño del riesgo y del error en su medición}

A continuación calculamos directamente la variabilidad del retorno acumulado, para el índice accionario Standard \& Poor's 500 de Estados Unidos para el período enero 1871-abril 2008, que excluye la debacle de septiembre de $2008^{15}$. Definimos "variabilidad” como la desviación estándar del retorno acumulado, denominada "DesvEstACC”, que es la raíz cuadrada de VarACC.

La línea punteada del centro en el Gráfico $\mathrm{N}^{0} 1$ muestra la variabilidad DesvEstACC del retorno acumulado considerando distintos horizontes sin traslape, previa conversión a logaritmos. El efecto del seguro accionario está incluido en el Gráfico $\mathrm{N}^{\circ} 1$. La primera lección del Gráfico $\mathrm{N}^{\circ} 1$ es que DesvEstACC, que mide la variabilidad intrínseca del retorno acumulado de las acciones, aumenta cuando el horizonte se hace mayor. Es decir, al invertir a plazos más largos, el riesgo de inversión acumulado es mayor, no menor. Los años malos no compensan siempre a los años buenos. Un motivo es que al crecer el horizonte, aumenta la probabilidad de tener muchos años malos seguidos.

La segunda lección de la línea central del Gráfico $\mathrm{N}^{\circ} 1$ es el enorme nivel absoluto que alcanza el riesgo intrínseco de las acciones

${ }^{15}$ Ese sitio actualiza continuamente los datos utilizados en su libro Irrational Exuberance, Princeton University Press, 2000, 2005. 
GRÁFICO No 1 1: INTERVALO DE CONFIANZA PARA LA DESVIACIÓN ESTÁNDAR DE LA RENTABILIDAD ACUMULADA DE UNA CARTERA ACCIONARIA, DE 1 A 6 AÑOS (Datos históricos EE.UU. 1871-2008)

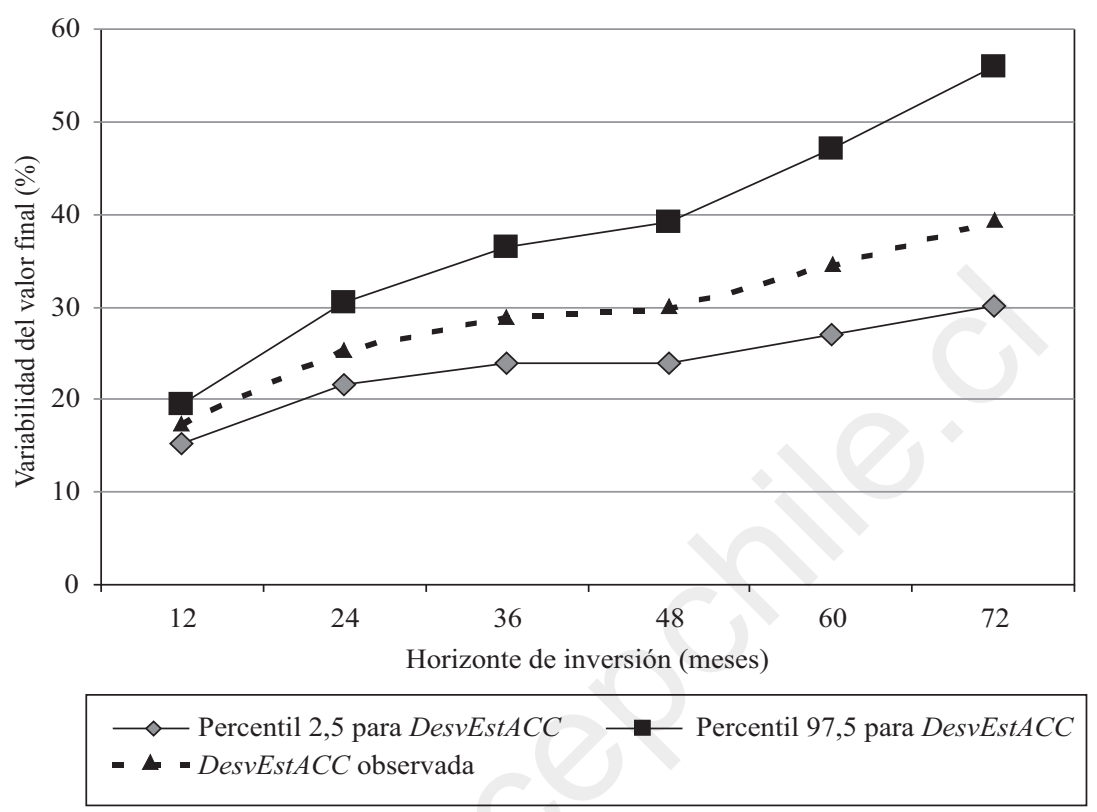

Fuente: Elaboración propia a partir de datos publicados por el profesor Robert Shiller, de la Universidad de Yale, en http://www.econ.yale.edu/ shiller/.

cuando los plazos de inversión son largos. Por ejemplo, para un horizonte de seis años, en promedio el valor final estará $40 \%$ por debajo ó $40 \%$ por encima del valor final medio.

El Gráfico N ${ }^{\circ} 1$ también cuantifica el error de estimación del riesgo DesvEstACC, originado en la escasez de observaciones. Este error no es pequeño a pesar de que contamos con 137 años de datos. Para medir esta incertidumbre se usa el concepto de "intervalo de confianza”. Para apreciar este concepto, contemple la distribución de frecuencias para los valores que toman las observaciones. Siempre es posible definir un rango o intervalo en el cual está contenido un cierto porcentaje (alto) de los resultados posibles de la variable, de acuerdo a su frecuencia empírica. El nivel de cobertura de este intervalo se fija por convención en 95\%. El Gráfico № 1 muestra los límites de cada intervalo de confianza, para cada plazo, usando las líneas percentil 2,5 y percentil 97,5. 
Para calcular un intervalo de confianza se requiere hacer algún supuesto sobre la forma de la distribución de frecuencias. En el caso donde las distintas observaciones del retorno acumulado se distribuyen lognormal ${ }^{16}$, la desviación estándar del logaritmo del retorno acumulado se distribuye de una manera conocida y disponible en tablas estadísticas, que permiten construir el intervalo de confianza que nos interesa ${ }^{17}$. El resultado está también en el Gráfico $\mathrm{N}^{\circ} 1$.

Se observa que cuando el horizonte es de un solo año, el intervalo de confianza es estrecho: con $95 \%$ de probabilidad, la verdadera desviación estándar está entre 16,4\% y 20,8\% (en logaritmo). Sin embargo, a medida que el horizonte aumenta, el número de observaciones independientes (no superpuestas) cae, lo cual amplía el intervalo de confianza. La independencia de las observaciones es muy importante para la precisión con que se estima un promedio. Si un asegurador de incendios desea estimar la tasa de siniestralidad a partir de datos de sólo 10 casas, sus datos son insuficientes. No aumenta sus datos diciendo que tiene datos de 9 grupos con 9 casas cada uno, si los diez grupos se forman a partir de las mismas 10 casas originales. Un mismo número de años de datos es menos informativo para el horizonte más largo (seis años), porque contiene sólo $22(=137 / 6)$ períodos de seis años que sean independientes entre sí (donde no haya traslape).

El Gráfico № 2 continúa este procedimiento para horizontes más largos, hasta treinta años. Se encuentra que para períodos de diez años o más, el riesgo de invertir en acciones sigue creciendo, no tanto en la dimensión intrínseca, pero sí en la dimensión de error de estimación. El intervalo de 95\% de confianza nos dice que la desviación estándar a treinta años está entre 31\% y 201\% del valor final. Éste es el punto que enfatizan Barberis (2000) y Pastor y Stambaugh (2009), y su importancia radica en que compensa el efecto del autoseguro accionario, que explicaremos más adelante. El Gráfico № 2 también revela una asimetría en el error de estimación de la desviación estándar intrínseca: es mucho mayor hacia valores altos que hacia valores bajos. El error de estimación no es tomado en cuenta por la fórmula (4), pues, como se advirtió, ella supone "que los números PPRA $A_{t}$ y VarACC son conocidos con exactitud”.

\footnotetext{
${ }^{16}$ No hacemos afirmación alguna respecto a la distribución del retorno dentro del horizonte o plazo.

${ }^{17}$ El teorema de Cochran dice que el producto del número $n$ de observaciones menos uno, por la desviación estándar al cuadrado observada en la muestra, dividido por la verdadera desviación estándar de la población elevada al cuadrado, se distribuye Ji-cuadrado con parámetro $(n-1)$.
} 
GRÁFICO No 2: INTERVALO DE CONFIANZA PARA LA DESVIACIÓN ESTÁNDAR DE LA RENTABILIDAD ACUMULADA DE UNA CARTERA ACCIONARIA, DE 1 A 30 AÑOS

(Datos históricos EE.UU. 1871-2008, sin traslape)
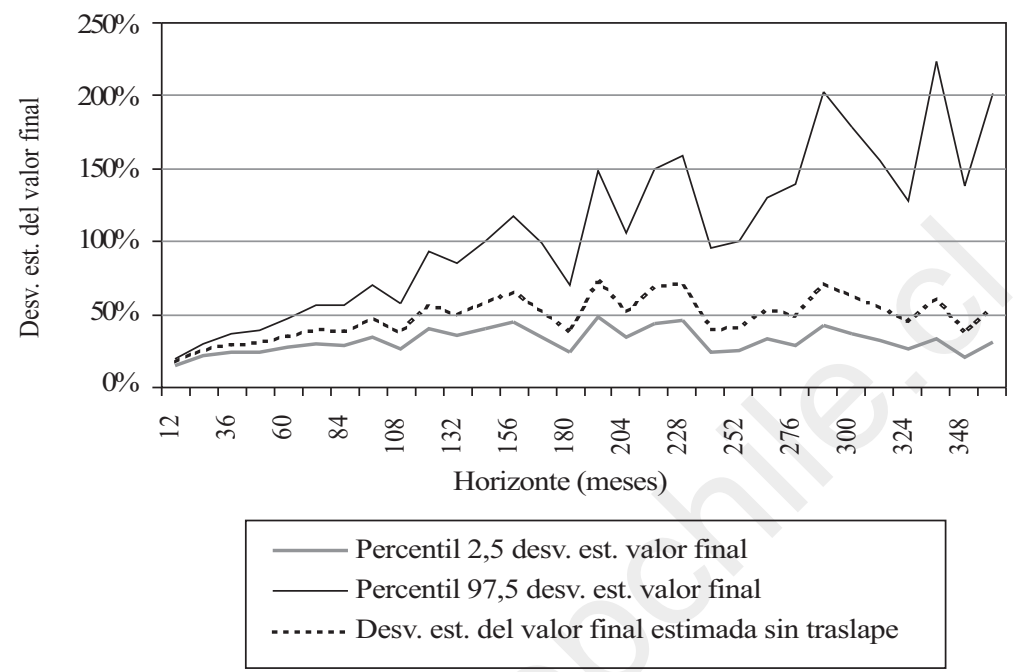

Fuente: Elaboración propia a partir de datos publicados en http://www.econ.yale.edu/ $\sim$ shiller/.

\section{Difusión en Chile de la creencia pro-accionaria}

Aquí documentamos cuán difundida está en Chile la recomendación de elevar la proporción invertida en acciones, sólo en razón de que el horizonte de inversión es largo. Las citas de la Introducción deben ser agregadas a esta evidencia.

\section{Evidencia 1}

Un reportaje del diario La Segunda de Santiago, 29 de mayo 2009, p. 45, informó que "los expertos afirman que las acciones rentan más que los títulos de renta fija en el largo plazo".

El reportaje no registró contrapreguntas a sus fuentes sobre el fundamento de esa afirmación. Los "expertos” no identificados cometieron el siguiente error: si en todos los escenarios posibles de rentabilidad de largo plazo, digamos a diez años plazo, las acciones rentaran más que la renta fija, entonces el verdadero riesgo de invertir en acciones sería nulo, porque las acciones vencerían a la renta fija en todos y cada uno de 
esos escenarios. Es decir, se incumpliría la ecuación (3), obtenida de la teoría económica. Y como indica la fórmula (4a), si RiesgoACC tendiera a cero, entonces la proporción óptima a invertir en acciones tendería a cifras muy altas.

\section{Evidencia 2}

El boletín "Multifondos No 24", de marzo de 2009, emitido por la Asociación de AFP, afirma que: "La tasa de reemplazo del salario de los trabajadores siempre es mayor cuando el fondo invierte en acciones, aunque más variable, que cuando sólo lo hace en renta fija”.

Para apreciar esto, recordemos que la "tasa de reemplazo del salario" es el cociente de la pensión y el salario imponible del mismo trabajador en su fase de actividad laboral. Entre otros factores, la tasa de reemplazo depende de la rentabilidad acumulada de las inversiones, que es lo que nos interesa aquí.

Nuevamente la afirmación contradice la teoría económica. Si en todos los escenarios posibles de rentabilidad ("siempre") las acciones rentaran más que la renta fija, entonces el verdadero riesgo de invertir en acciones sería nulo: las acciones vencerían a la renta fija en todos y cada uno de esos escenarios. No importa que el exceso por el cual las acciones vencen a la renta fija sea grande, pequeño o variable, mientras venzan en todos los escenarios. Ese texto postula que se incumple la ecuación (3), obtenida de la teoría económica, sólo en razón del plazo largo de la inversión.

\section{Evidencia 3}

Una AFP chilena grande sostenía en su página web, el 18 de junio de 2009, que "Mientras mayor sea el horizonte de tiempo es más recomendable invertir en un fondo con mayor riesgo [entendemos que con mayor proporción en acciones], debido a que en el largo plazo ofrece un retorno esperado [entendemos promedio] mayor".

En el lenguaje de este trabajo, esa página afirma primero que $P P R A_{t}$ es positivo para horizontes largos de inversión. Si bien es correcto, ya vimos que eso no justifica la recomendación. En efecto, falta verificar cuánto crece el riesgo al aumentar el horizonte, y cuál crece más. Preocupa que simplemente se omita el tema del riesgo. 
Segundo, asocia un plazo largo de inversión con "un retorno promedio mayor". Esta asociación es falsa, y no se sabe de autores que la hayan defendido.

En suma, esta sección documenta que en Chile ha estado ampliamente difundida la recomendación de elevar la proporción invertida en acciones, sólo en razón de que el plazo de inversión es largo.

\section{La evidencia histórica de J. Siegel y su refutación}

En 1994 Jeremy Siegel, profesor de la Universidad de Pennsylvania, aplicó un método nuevo para determinar cuán precisa sería la predicción del precio de las acciones para horizontes largos, de 10 y 20 años: analizó 192 años de datos de retornos (desde 1802) para bonos nominales y acciones en Estados Unidos. Encontró una sorpresa: en cualquier secuencia de 20 años contiguos en el tiempo, la rentabilidad acumulada de las acciones venció a la rentabilidad de los bonos nominales "casi" siempre. El "casi" es porque en el 8,5\% de las secuencias, los bonos nominales vencieron a las acciones ${ }^{18}$. Siegel restó importancia al "casi” por un motivo plausible: la última secuencia de 30 años en la cual las acciones fueron vencidas por los bonos nominales fue 1831-1861.

Parte de los malentendidos se debe a que Siegel calificó esta situación como "dominancia" de las acciones sobre los bonos nominales (ver Siegel 1998, pp. 5 y 11). Esto es incorrecto en términos estrictos, porque ese $8,5 \%$ de secuencias de 20 años continuos donde vencieron los bonos impide calificar la situación de “dominancia” y genera riesgo verdadero a las acciones.

Siegel (1998) propuso dos hipótesis para explicar estos hechos históricos:

1. La inflación dañó mucho a los retornos de los bonos porque ellos eran nominales, y en particular los dañó más que a los retornos de las acciones, en plazos largos de diez años o más, una vez que el abandono del patrón metálico a favor del papel moneda (dinero fiduciario, sin respaldo en metálico) permitió niveles inflacionarios de largo plazo superiores a los de la historia previa. El abandono del patrón metálico para la moneda inauguró un régimen en el cual los inversionistas no tenían experiencia, hecho que habría permitido engañarlos por un tiempo prolongado.

${ }^{18}$ En la muestra 1871-1996, los bonos vencieron en el 5,6\% de los grupos de 20 años contiguos. 
2. Siegel advirtió que al término de la Segunda Guerra Mundial, después que se hizo obvio que se había acelerado la inflación, los inversionistas tampoco exigieron retornos mayores a los títulos nominales cortos. Propuso explicar esto sobre la base de que muchos inversionistas de esa generación vivieron la debacle de la Gran Depresión (el Dow Jones cayó 89\% entre 1929 y 1932, 34 meses de cima a sima) y, en una reacción exagerada de aversión al riesgo exagerada, muchos optaron por rechazar las acciones del todo.

El descubrimiento de Siegel y sus afirmaciones de dominancia desataron en Wall Street y otros centros financieros una fiebre de recomendaciones para elevar la fracción de las carteras mantenida en acciones.

Sin embargo, ya en 1998 Siegel reconoció que si las acciones hubieran competido con una cartera de bonos indexados al IPC de diez años de plazo promedio, entonces las acciones no habrían sido dominantes. En concreto, Siegel reportó que desde 1926 el retorno acumulado en diez años de bonos hipotéticos indexados al IPC (son hipotéticos porque en Estados Unidos esos bonos fueron creados recién en 1997) habría vencido al retorno acumulado de las acciones en jel $25 \%$ ! de las secuencias de diez años contiguos (Siegel 1998, p. 38).

El aumento desde $8,5 \%$ a $25 \%$ se explica por el cambio de inversión alternativa, desde bonos nominales a bonos indexados al IPC. Los bonos indexados al IPC están perfectamente protegidos del efecto de la inflación, incluso mejor que las acciones ${ }^{19}$, lo cual hace inaplicable la primera hipótesis, ya citada, para explicar los hechos históricos. Es decir, la dominancia de las acciones sobre la renta fija está mucho más lejana de la realidad cuando se compara con bonos indexados al IPC que con bonos nominales, ambos de largo plazo ${ }^{20}$.

Los bonos de largo plazo indexados al IPC son la inversión alternativa relevante hoy para los inversionistas de todo el mundo, pues desde hace unos diez años existe un amplio grupo de gobiernos que emiten bonos de largo plazo indexados al IPC. Ello permitió al Deutsche Bank crear el índice DB Global Government ex-US Inflation Linked Bond Capped Index, que es un índice de bonos largos indexados emitidos por los siguientes 18 Estados: Australia, Brasil, Canadá,

${ }^{19}$ Diversos estudios empíricos para Estados Unidos encuentran que al aumentar la inflación, el Banco Central tiende a restringir la política monetaria, lo cual tiende a reducir el crecimiento y ello reduce el precio de las acciones por uno a tres años.

${ }^{20}$ Es lamentable, por las confusiones que genera, que Siegel no haya retirado el calificativo de "dominante" a las acciones, respecto de los bonos indexados al IPC. 
Chile, Francia, Alemania, Grecia, Israel, Italia, Japón, México, Polonia, Sudáfrica, Corea del Sur, Suecia, Turquía y Uruguay. A ellos se debe agregar Estados Unidos con su bono TIPS que empezó a emitir en 1997. En 2008 se crearon Exchange Traded Funds (ETF) (acciones que replican el fondo indicado) para este índice de Deutsche Bank y para un índice para los TIPS ${ }^{21}$. Todo inversionista moderno tiene acceso a estos instrumentos, que son definitivamente menos riesgosos que las acciones en el largo plazo.

En Chile, los bonos de largo plazo indexados al IPC son una inversión alternativa a las acciones aun más pertinente, pues cuentan con uno de los mercados más amplios del mundo de bonos de largo plazo protegidos de la inflación de IPC y emitidos por empresas privadas, bancos privados y hogares (letras hipotecarias).

\section{Evidencia de países distintos de los Estados Unidos}

El resultado de Siegel, referido a que los bonos de largo plazo nominales siempre fueron vencidos por las acciones en secuencias de 30 años después de 1862, ha sido rechazado por los autores que ampliaron los datos de otros países diferentes de Estados Unidos.

En 2003 Phillipe Jorion, profesor de Finanzas de la Universidad de California, reunió retornos accionarios para 30 países, con al menos 60 años de datos para cada uno. Para cada país calculó la frecuencia con que las acciones lograron una ganancia de capital acumulativa inferior a cero (real) en diez años contiguos. Encontró que la mediana de esta probabilidad entre 30 países fue ¡ $48 \%$, una cifra enorme!

Además, para aquellos 16 países para los cuales tiene datos de dividendos accionarios, que permiten calcular el retorno total (dividendo más ganancia de capital), encontró lo siguiente: en el $5 \%$ más negativo de los escenarios de retorno acumulativo en diez años contiguos, la pérdida fue de $35 \%$ en el país mediano. En el 5\% más negativo de los escenarios, el inversionista perdió en promedio 4,22\% real en cada año, durante diez años seguidos.

El trabajo de Jorion sufre de un sesgo, pues no compara el retorno accionario con el retorno efectivo de los bonos de largo plazo indexados al IPC, sino con un retorno teórico de cero por ciento real cuyo único objeto es limpiar el efecto de la inflación. Este procedimiento equivale a comparar con un bono indexado de largo plazo que rinde

${ }^{21}$ Ver https://www.spdrs.com/. 
CUADRO N ${ }^{\circ}$ 1: $\quad$ RENDIMIENTO DE BONOS DE GOBIERNOS, REAJUSTABLES POR INFLACIÓN Y A 10 AÑOS

(Rendimiento futuro, implícito en los precios del mercado secundario, en $\%$ anual)

\begin{tabular}{lrrrrrrr}
\hline Año & Canadá & Suecia & Francia & Australia & EE.UU. & Chile & México \\
\hline 2000 & & & & & & & \\
2001 & 3,74 & 4,08 & n.d. & 3,53 & 4,05 & n.d. & n.d. \\
2002 & 3,58 & 3,73 & n.d. & 3,36 & 3,33 & n.d. & n.d. \\
2003 & 3,51 & 3,53 & n.d. & 3,44 & 2,86 & 4,02 & n.d. \\
2004 & 3,00 & 2,84 & n.d. & 3,36 & 2,01 & 3,96 & 4,48 \\
2005 & 2,29 & 2,41 & 2,12 & 3,14 & 1,81 & 3,54 & 4,73 \\
2006 & 1,72 & 1,67 & 1,49 & 2,60 & 1,80 & 2,72 & 4,86 \\
2007 & 1,65 & 1,76 & 1,71 & 2,33 & 2,31 & 3,02 & 4,18 \\
2008 & 1,98 & 1,87 & 2,12 & 2,54 & 2,28 & 2,91 & 3,59 \\
Media & 1,88 & 1,74 & 2,16 & 2,38 & 1,75 & 3,13 & 3,99 \\
Dif con Chile en & 2,59 & 2,63 & 1,92 & 2,96 & 2,47 & 3,33 & 4,31 \\
$\quad$ años en común & $-1,04$ & $-1,07$ & $-1,19$ & $-0,50$ & $-1,21$ & 0,00 & 1,09 \\
\hline
\end{tabular}

Nota: Los bonos franceses se reajustan por un índice de inflación europeo. Francia emite otros bonos que se reajustan por la inflación local, pero no existe un benchmark único.

Fuente: Bloomberg.

$0 \%$ real. Una tasa de $0 \%$ real es artificialmente baja, como muestra el Cuadro $\mathrm{N}^{\mathrm{o}} 1$.

El Cuadro $\mathrm{N}^{\circ} 1$ sugiere que un estándar de comparación realista para el rendimiento real de las acciones sería $2 \%$ real anual. Luego, el supuesto de Jorion de que la alternativa a las acciones rinde $0 \%$ favorece artificialmente a las acciones.

Por su parte, los economistas E. Dimson, P. Marsh y M. Staunton reunieron retornos accionarios reales para 103 años en cada uno de los 16 países. Los tres son profesores en el London Business School. En Dimson, Marsh y Staunton (2002) ellos reportan el retorno accionario total, incluyendo los dividendos de las acciones, para esos 16 países, ampliando la muestra desde los 60 años cubiertos por Jorion hasta 103 años. Respecto al retorno que tendría la inversión alternativa, presentan las dos alternativas que existieron históricamente y que hoy han perdido relevancia: bonos de corto plazo nominales, y bonos de largo plazo nominales.

Mirando hacia adelante, para cualquier inversionista moderno la alternativa relevante es el retorno de los bonos de largo plazo indexados 
al IPC. En este estudio nos aproximamos a eso fijando diversos valores para este último retorno, que no se alejan de la evidencia mostrada en el Cuadro $\mathrm{N}^{\circ} 1$.

En el Gráfico $\mathrm{N}^{\circ} 3$ de Dimson et al. (2004) se observa que en 10 de sus 16 países (es decir, en la mayoría) el retorno acumulado en 20 años fue inferior a 2,0\% real anual en $25 \%$ o más de las secuencias de 20 años contiguos.

Nuevamente, la evidencia empírica es abrumadora en cuanto a que las acciones sufren un riesgo significativo de ser vencidas por bonos de largo plazo indexados al IPC, para plazos de inversión de 20 años.

En suma, la evidencia empírica rechaza la hipótesis de que el retorno accionario "domina" al retorno de acumulado de las inversiones alternativas relevantes hoy, es decir las vence en todos los escenarios. En ausencia de dominancia, la elección del porcentaje de acciones en la cartera depende del grado de aversión al riesgo del inversionista o afiliado.

GRÁFICO N 3: DISTRIBUCIÓN DE RETORNOS ACCIONARIOS REALES SEGÚN DIMSON ET AL. 2004

Retorno real anualizado (\%)

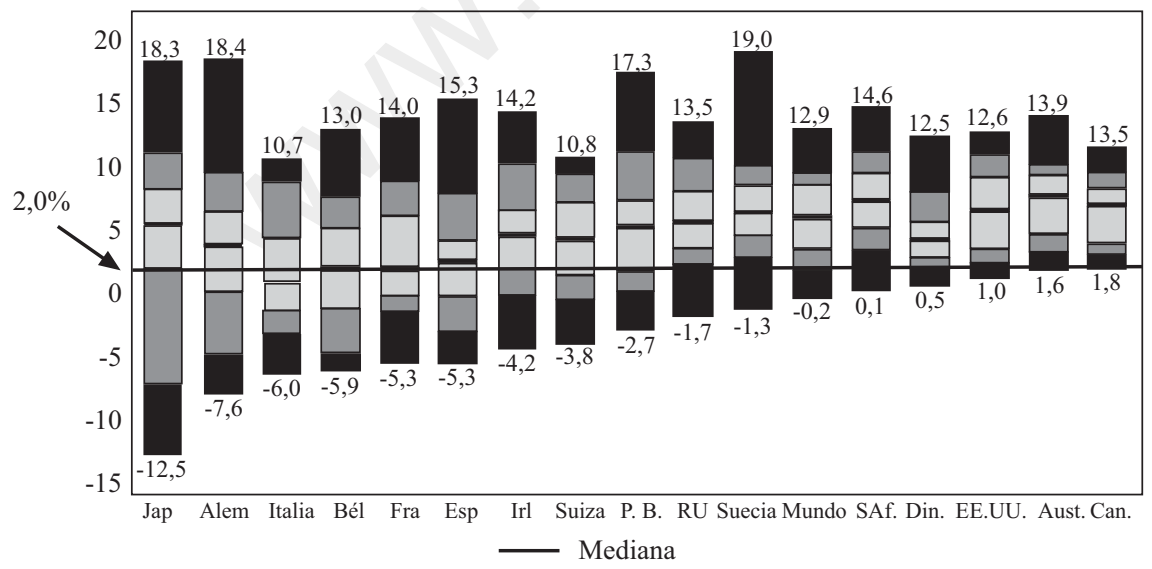

Nota: Línea gruesa a la altura de 2,5\% real anual: retorno medio de una cartera de renta fija; las líneas horizontales que dividen cada barra indican percentiles en el siguiente orden, de arriba abajo: 100\%, 90\%, 75\%, mediana, 25\%, 10\%.

Fuente: Elaboración propia, superponiendo línea de 2,0\% real sobre la Figura 3 de Dimson et al. (2004). 


\section{Autoseguro accionario versus riesgo muestral y riesgo de predicción}

A partir de 1998 el debate se trasladó a un estadio superior. Se inició el análisis de una rehabilitación parcial del consejo pro-accionario, sobre una base nueva: se demostró que el retorno accionario exhibe un autoseguro (natural hedge) parcial. Esta postura fue liderada por Campbell y Viceira (1999) y Cochrane (2008). En el lenguaje de la recuperación de las pérdidas accionarias, este autoseguro hace que el valor final de la cartera accionaria goce de una variabilidad reducida respecto al caso sin autoseguro. El carácter parcial del autoseguro indica que, en una fracción importante de casos, el valor final de la inversión accionaria resulta inferior al valor final de una cartera de renta fija indexada al IPC, aun para plazos largos. En este debate nadie postula que exista dominancia de las acciones sobre la renta fija, como hizo Siegel.

\subsection{Autoseguro cuando el horizonte cubre dos o más períodos}

Es un hecho que en algunos años los inversionistas esperan altas rentabilidades (están optimistas) y en otros esperan una rentabilidad modesta (están pesimistas). Por lo tanto, el PPRA formado en la fecha $t$ es distinto que el formado en la fecha $t+1$. El promedio del retorno accionario para el siguiente período, considerando los escenarios posibles, varía en el tiempo. Esto sólo ocurre cuando se admite que el contexto es multiperíodo.

Para precisar ideas, supongamos que el premio por riesgo accionario que perciben los inversionistas varía en el tiempo, pero siempre alrededor de un mismo promedio de largo plazo, que no varía en el tiempo.

$P P R A_{t}=P P R A L P+\varepsilon_{t}$ con $\mathrm{E}\left[\varepsilon_{t}\right]=0$ y $\mathrm{E}_{\mathrm{t}}\left[\varepsilon_{\mathrm{t}} \cdot \varepsilon_{\mathrm{t}-\mathrm{k}}\right]=0$, todo $\mathrm{k}$,

donde:

PPRALP es la expectativa de largo plazo para el premio por riesgo accionario, que se mantiene fija en el tiempo.

$\varepsilon_{t}$ es la desviación en el período $t$, entre la expectativa de retornos para ese período (el $P P R A_{t}$, que promedia los $p p r a_{t+1}$ efectivos vistos desde la fecha $t$ ) y la expectativa de largo plazo (PPRALP). 
En el caso simple analizado aquí, se supone también que las desviaciones $\varepsilon_{t}$ tienen un promedio cero entre todos los períodos (promedio incondicional). También se supone que esas desviaciones son independientes entre sí en el tiempo.

Además, definamos el "error de predicción del exceso de retorno accionario", un período adelante. Este error es la diferencia entre ppra $_{t+1}{ }^{\text {efectivo }}$ y $P P R A_{t}$. Llamemos a este error $u_{t+1}$. Según la propia definición de $P P R A_{t}$ el promedio del error de predicción, entre los distintos escenarios posibles, es cero ${ }^{22}$.

Ahora combinemos ambos conceptos. Supongamos que en promedio, cuando las acciones suben de precio (el error de predicción $u_{t+1}$ resulta ser positivo), en el siguiente período la expectativa de retorno para el período subsiguiente tiende a ser menor que la expectativa de largo plazo PPRALP, y por tanto la desviación $\varepsilon_{t+1}$ es negativa.

En el caso descrito, el error de predicción $u_{t+1}$ covaría negativamente con la desviación $\varepsilon_{t+1}$. Si esta covarianza fuera cero, una sorpresa positiva tendría igual probabilidad de ser seguida por otra sorpresa positiva, que si la sorpresa inicial hubiera sido negativa. Hay evidencia empírica en contra de ésa, y a favor de que esta covarianza es negativa.

En el caso de covarianza negativa, los errores de predicción del retorno accionario efectivo varían en forma coordinada en el tiempo con la expectativa de retornos para el período subsiguiente, aunque sin certeza respecto de que la reversión se dé. Esto implica que el retorno accionario efectivo varía en el tiempo de una manera que revierte parcialmente las desviaciones del período anterior más cercano ${ }^{23}$. Este comportamiento de reversión reduce el riesgo del retorno accionario acumulado de los dos períodos contiguos ${ }^{24}$. Ésta es la reducción de riesgo que se describe como "autoseguro" (natural hedge) parcial.

Un atributo del autoseguro accionario es que opera en forma automática, aunque el inversionista no rebalancee su riqueza cada período. Esto es útil, porque permite minimizar los costos de transacción por rotación de activos. Esto no quiere decir que no sea conveniente

\footnotetext{
${ }^{22}$ En términos técnicos, se cumple $E_{t}\left[\right.$ ppra $\left.^{\text {efectivo }}{ }_{t+1}-P P R A_{t}\right] \equiv E_{t}\left[u_{t+1}\right]=0$, y $E_{t}\left[u_{t} \cdot u_{t-k}\right]=0 \forall k$. $\equiv \sigma_{\mu \varepsilon}<0$.

${ }^{23}$ En términos técnicos, $\operatorname{Cov}_{\mathrm{t}}\left(\right.$ ppra $^{\text {efectivo }}{ }_{t+1}$, ppra $\left.^{\text {efectivo }}{ }_{t+2}\right)=\operatorname{Cov}_{\mathrm{t}}\left(u_{t+1}, \varepsilon_{t+1}\right)$

${ }^{24}$ En la literatura de finanzas se dice que este autoseguro origina una "demanda por cobertura intertemporal”.
} 
rebalancear en cada período: es conveniente, pues si $P P R A_{t}$ varía, es óptimo modificar la fracción accionaria, tal como sugiere (4). El punto es que, aunque no rebalancee por otras razones, el inversionista en acciones igual gana el autoseguro.

Las nuevas teorías desarrolladas a partir de 1998 por Campbell y Viceira (2002) modelan este autoseguro. Otros autores modelaron de nuevo la maximización de la utilidad esperada del inversionista en este escenario multiperíodo, tomando en cuenta este autoseguro, y lograron soluciones analíticas para ciertos casos. Ellas sustituyen la solución (4) por otras más complejas ${ }^{25}$.

\subsection{Predictibilidad del retorno accionario}

En una segunda aproximación, los inversionistas afinan su predicción usando modelos para predecir PPRA y DesvEstACC. Por ejemplo, Pastor y Stambaugh (2008) desarrollan una teoría general para predecir expectativas subjetivas a partir de datos sobre múltiples variables observables.

Para las acciones, la mejor variable predictiva es la razón dividendo a precios. En el caso de Estados Unidos hay datos mensuales de calidad aceptable a partir de 1871 para el precio de una cartera con las 500 acciones más transadas, similar al actual S\&P500. Con ella se puede construir la razón dividendo a precios y la razón precio a utilidad (la utilidad es simplemente el dividendo más la utilidad retenida). Estos datos están publicados por Robert Shiller, profesor de la Universidad de Yale, en su página web y son reproducidos en nuestro Gráfico $\mathrm{N}^{\circ} 4$.

${ }^{25}$ En el caso particular dado por (5), el autoseguro no puede ser aprovechado variando en forma oscilante la fracción invertida en acciones. Pero puede ser aprovechado aumentando en forma permanente la fracción accionaria. Prueba: ver Campbell y Viceira (2002), pp. 97 y 98. En el caso de autoseguro dado por (5a) se cumple en la notación de esos autores, $\phi,=0, P P R A t=\mathrm{x}_{\mathrm{t}} \mathrm{y} P P R A L P=\mu$. Así, sus ecs. 4.15, $4.18 \mathrm{y}$ 4.19 entregan:

$$
\alpha_{i}^{*}=\frac{1}{\gamma} \cdot\left(\frac{P P R A t}{\sigma_{u}^{2}}\right)+0+\left(\frac{-\sigma_{\eta u}}{\sigma_{u}^{2}}\right)\left(1-\frac{1}{\gamma}\right) \cdot\left[\frac{b_{1}+2 \cdot P P R A L P \cdot b_{2}}{1-\psi}\right]
$$

El primer término replica a (4), pero el segundo término muestra el efecto del autoseguro. En el caso empíricamente relevante, $\psi<1, \mathrm{~b}_{1}>0$ y $\mathrm{b}_{2}>0$. Se observa que el segundo término no varía en el tiempo en este caso, lo cual indica que la forma óptima de aprovechar el autoseguro es simplemente elevar la fracción accionaria en forma permanente. Si $\phi>0$ convendría además oscilar la fracción en acciones. 
GRÁFICO N 4: RAZÓN PRECIO/UTILIDAD BASADA EN UN PROMEDIO MÓVIL DE LAS UTILIDADES EN LOS ÚLTIMOS 10 AÑOS

(Datos de Robert Shiller para el S\&P 500 enero 1871 - enero 2010) ${ }^{26}$

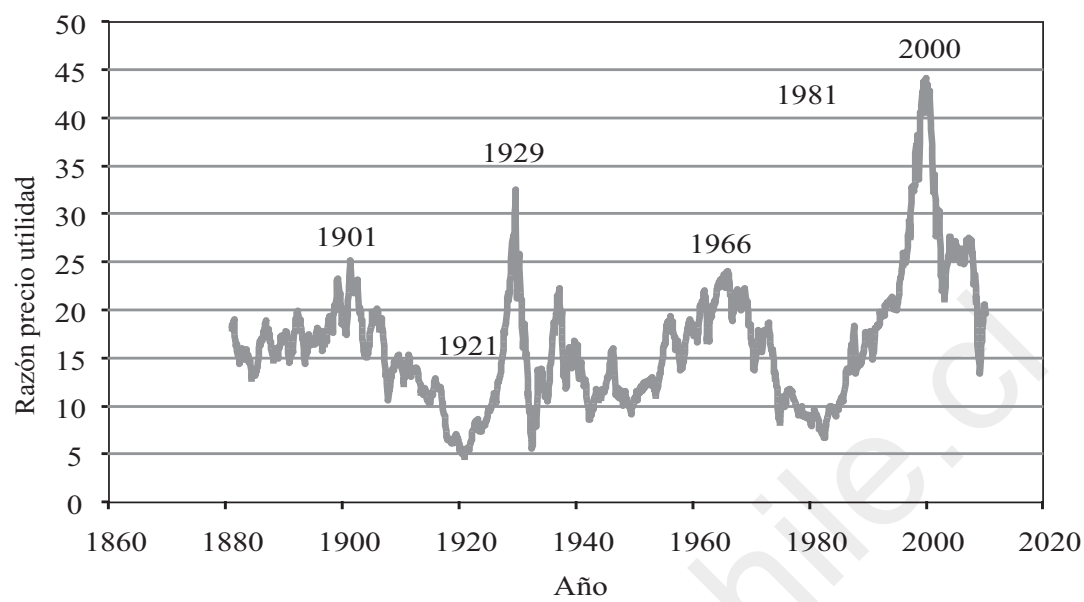

Fuente: Robert Shiller, gráfico “Price-Earning Ratio (CAPE) (1860-2020)”, tomado del sitio en internet de actualización de su libro Irrational Exuberance (Princeton University Press, 2005, segunda edición): Disponible en http://www.econ.yale.edu/ shiller/.

El Gráfico No 4 revela que la razón dividendo a precios para las acciones no ha crecido ni decrecido indefinidamente en el tiempo. Esto implica que la serie tiende a volver (a revertir) a un valor de largo plazo. Por lo tanto, las variaciones de la razón dividendo a precios son predecibles parcialmente comparando el valor de esa misma razón en el período anterior y la razón de largo plazo.

Analice ahora una descomposición de esa predictibilidad entre dividendos y precios. Existe sólida evidencia de que la tasa de crecimiento del monto real de los dividendos accionarios no es predecible. Como la razón dividendo a precios sí es predecible, esto implica, necesariamente, que el precio futuro de las acciones es predecible. $\mathrm{Si}$ en el largo plazo los precios deben crecer a la misma tasa que los dividendos, entonces el retorno accionario un período adelante, promediando entre los escenarios posibles, varía en el tiempo de una manera predecible: revirtiendo las desviaciones en la razón dividendo a precios (Cochrane, 2008).

${ }^{26}$ Shiller también entrega el IPC mensual de los Estados Unidos y sobre los dividendos, lo cual permite construir los retornos totales reales de una cartera accionaria, con reinversión total de dividendos, antes de comisiones e impuestos. 
Para ilustrar estas ideas, Campbell y Viceira (2002, cap. 4) predicen el premio por riesgo accionario efectivo (en logaritmo) a partir de 119 datos anuales para Estados Unidos (1890-1998), con la siguiente ecuación aplicada a los datos históricos:

ppra $^{\text {efectivo }}{ }_{t+1}=\beta_{1} \cdot \ln (D / P)_{t}+\beta_{2} \cdot$ ppra $^{\text {efectivo }}+\varepsilon_{t+1} ; \mathrm{R}^{2}=0,052$

donde:

$\ln (D / P)_{t}=$ logaritmo de la razón dividendos a precio, para las acciones.

$\beta_{1}=$ coeficiente estimado a partir de los datos históricos. Encuentran que $\beta_{1}$ es una variable aleatoria con una media igual a $0,135 \mathrm{y}$ una desviación estándar de 0,0565. El intervalo de confianza al 95\% para el coeficiente $\beta_{1}$ es $(0,024 ; 0,246)^{27}$.

$\beta_{2}=$ otro coeficiente estimado. Encuentran que $\beta_{2}$ es una variable aleatoria con una media igual a 0,080 y una desviación estándar igual a 0,124 . El intervalo de confianza al $95 \%$ para el coeficiente $\beta_{2}$ es $(-0,163 ; 0,322)$.

$\varepsilon=$ error de predicción, cuya media es cero y su desviación estándar es $0,1898^{28}$.

Las críticas de carácter estadístico, que argumentaron que las predicciones del retorno accionario basadas en la razón dividendo a precio son poco robustas, fueron refutadas magistralmente por Cochrane (2008).

Este ejercicio confirma que la razón dividendo a precios, observada en $t$, ayuda a predecir el premio por riesgo accionario efectivo en $t+1$, pues $\beta_{1}$ es significativamente distinto de cero. Al mismo tiempo, ello no impide que el error de predicción de la ecuación sea sustancial, pues el error $\varepsilon$ tiene una desviación estándar de 18,98\% de rentabilidad anual.

\subsection{Rehabilitación del consejo pro-accionario}

La nueva teoría de cartera multiperíodo indica que es conveniente aprovechar las variaciones predichas de $P P R A_{t}$ de dos maneras: (i) aumentando la fracción accionaria promedio en el tiempo, para aprove-

\footnotetext{
${ }^{27}$ Para obtener ese intervalo de confianza se usa la fórmula: rango $\beta 1=$ media $\beta 1 \pm 1,96 \mathrm{x}($ DesvEst $\beta 1)$.

${ }^{28}$ La desviación estándar de $\varepsilon$ se obtiene de la fórmula $\mathrm{s}^{2} \varepsilon=\left(1-\mathrm{R}^{2}\right)$ $\left(\operatorname{Var}\left(\right.\right.$ ppra $\left.^{\mathrm{e}}\right)+\operatorname{Media}^{2}\left(\right.$ ppra $\left.\left.^{\mathrm{e}}\right)\right) \mathrm{n} /(\mathrm{n}-2)$, y de los datos de Campbell y Viceira (2002, p. 104) en cuanto a que $\operatorname{Var}($ PPRA $)=(0,1811)^{2}$, Media $\left(\right.$ pprae $\left.^{\mathrm{e}}\right)=0,0674, \mathrm{n}=119 \mathrm{y} \mathrm{R} \mathrm{R}^{2}=0,052$.
} 
char el componente de autoseguro, y (ii) variando en forma oscilante la fracción invertida en acciones ${ }^{29}$

Estas recomendaciones fueron tomadas en serio por algunos de los autores de esta línea de investigación. Por ello afirmamos que estos autores rehabilitaron el consejo pro-accionario sobre la base del autoseguro accionario. Destacan en ello los profesores John Campbell y Luis Viceira, ambos de la Universidad de Harvard, y el profesor John Cochrane, de la Universidad de Chicago.

Reportamos las dos recomendaciones que extraen Campbell, Chan y Viceira de este hallazgo. En primer lugar, recomiendan asignar a acciones los porcentajes del Cuadro $\mathrm{N}^{\circ} 2$, cuando la alternativa es invertir en bonos perpetuos indexados al IPC que rinden $0 \%$.

En nuestra opinión, la recomendación del Cuadro $\mathrm{N}^{\circ} 2$ es casi tan extrema como que hizo que J. Siegel, en 1994, recomendara subir muy drásticamente la fracción destinada a acciones, en las cifras registradas en la última columna. Por ejemplo, en el caso razonable de aversión al riesgo con coeficiente 5, Campbell, Chan y Viceira recomiendan invertir el 192\% del patrimonio en acciones. Es decir, reco-

CUADRO N ${ }^{\circ}$ 2: $\quad$ FRACCIÓN ÓPTIMA EN ACCIONES RECOMENDADA POR CAMPBELL, CHAN $\mathrm{Y}_{\text {VICEIRA }}^{30}$

\begin{tabular}{lccc}
\hline $\begin{array}{c}\text { Coeficiente de } \\
\text { aversión al } \\
\text { riesgo }(\gamma)\end{array}$ & $\begin{array}{c}\text { Fracción en acciones } \\
\text { recomendada por } \\
\text { C. y V. argumentando } \\
\text { el autoseguro accionario }\end{array}$ & $\begin{array}{c}\text { Fracción óptima en } \\
\text { acciones si no existiera } \\
\text { autoseguro accionario } \\
\left(\alpha^{*}\right)\end{array}$ & $\begin{array}{c}\text { Incremento en fracción } \\
\text { accionaria recomendada, } \\
\text { debido a la existencia } \\
\text { del autoseguro }\end{array}$ \\
\hline 5 & $307 \%$ & $165 \%$ & 142 puntos porcentuales \\
20 & $192 \%$ & $67 \%$ & 125 puntos porcentuales \\
5 & $76 \%$ & $18 \%$ & 58 puntos porcentuales
\end{tabular}

Nota: Una cifra superior a $100 \%$ se interpreta como que se recomienda endeudar al fondo de pensiones y usar los recursos del préstamo para adquirir más acciones.

Fuente: Elaboración propia a partir de la Tabla $N^{\circ} 4$, Panel B, de Campbell, Chan y Viceira (2003), p. 71.

${ }^{29}$ Un ajuste oscilante y oportuno de la fracción invertida en acciones refuerza la recomendación de elevar el porcentaje promedio mantenido en acciones (promedio en el tiempo).

${ }^{30}$ Ellos suponen que la deuda del fondo de pensiones paga un spread nulo respecto al retorno de renta fija que reciben los inversionistas. Ver efecto de levantar este supuesto en Willen y Kluber (2006). 
miendan invertir todo el patrimonio en acciones, y además endeudarse en 92\% del patrimonio con el fin de destinar todos los recursos obtenidos de ese crédito a comprar más acciones hasta completar 192\%.

Incluso para el caso de aversión al riesgo extrema, de $\gamma=20$, Campbell, Chan y Viceira recomiendan subir el porcentaje accionario en 58 puntos porcentuales, lo que en el sistema chileno de multifondos equivale a pasar del fondo $\mathrm{D}$ al $\mathrm{A}$.

Segundo, Campbell, Chan y Viceira recomiendan como "óptimo” aplicar violentas fluctuaciones a la fracción accionaria a lo largo del tiempo, como muestra el Gráfico $\mathrm{N}^{\circ} 5$, con el fin de aprovechar la predictibilidad en el precio de las acciones en el largo plazo.

El Gráfico No 5 revela que Campbell, Chan y Viceira recomiendan oscilar la fracción accionaria entre valores tan extremos como $300 \%$ y $-100 \%$, con una alta frecuencia trimestral (ésta es la unidad de tiempo en el Gráfico $\mathrm{N}^{\circ}$ 5). Esta frenética estrategia de timing se explica por las fuertes fluctuaciones en la razón dividendo a precios en el $p_{p r a}$ efectivo $^{\text {y }}$ todavía no consideran la incertidumbre sobre los coeficientes $\beta_{1}$ y $\beta_{2}$. Veremos que estas audaces recomendaciones han sido objeto de sólidas críticas teóricas y empíricas.
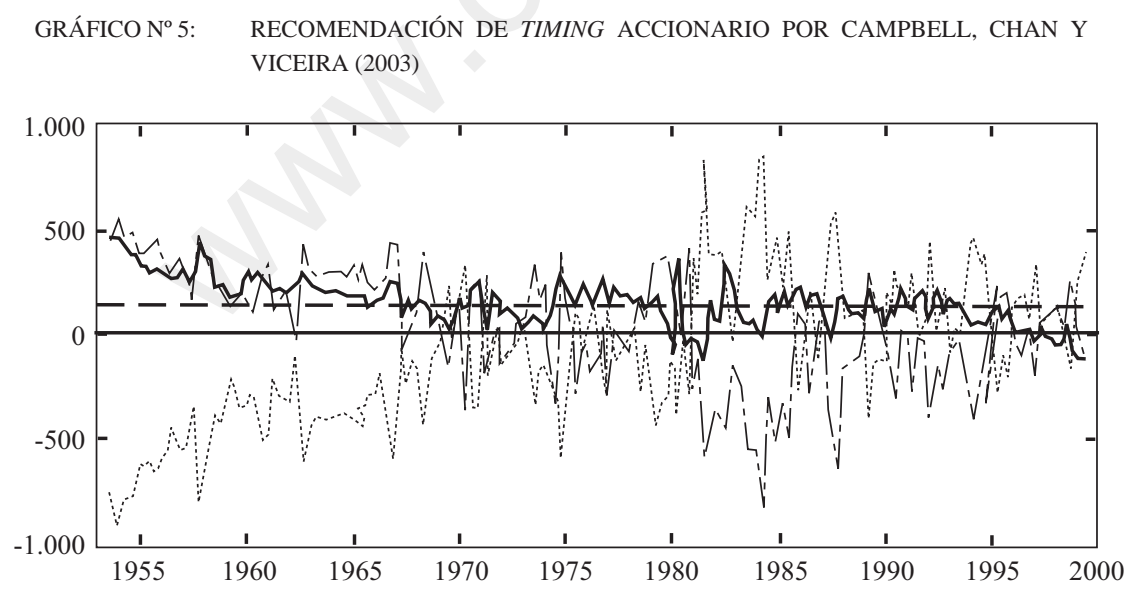

\begin{tabular}{|llll|}
\hline - deuda corta $\mathrm{a} \quad$ acciones & $\cdots \cdots$ & bonos largos \\
\hline
\end{tabular}

Nota: La línea de guiones marca el 100\% del patrimonio y la línea gruesa el 0\%.

a) Bonos nominales a menos de un año del Tesoro de los Estados Unidos.

b) Bonos nominales de largo plazo del Tesoro de los Estados Unidos.

Fuente: Campbell, Chan y Viceira (2003), Figura 3, panel superior, p. 67. 


\subsection{Crítica 1: el riesgo muestral aumenta con el horizonte de inversión}

Dimson et al. (2004) hicieron ver que el número de observaciones disponibles respecto del pasado depende del horizonte de inversión. Por ejemplo, para un horizonte de dos años, el período 18712008 ofrece $(137 / 2=)$ 68,5 observaciones independientes. Para un horizonte de 20 años, sólo ofrece $(137 / 20=)$ 6,85 observaciones independientes.

Traslapar los períodos no aumenta el número de observaciones independientes. Por ejemplo, el retorno acumulado por las acciones en el período que va del 1 de enero de 1871 al 31 de diciembre de 1890, y el retorno acumulado por las acciones en el período que va del 1 de febrero de 1871 al 30 de enero de 1891, tienen un traslape de 99,2\%, pues hay 238 de 240 meses en común. El traslape ayuda sólo cuando "sobra” una fracción de período.

Otro aspecto es que el aprendizaje es más lento respecto de retornos a plazos mayores. Se necesita esperar diez años para obtener una nueva observación independiente de retorno acumulado a diez años, que nos permita reducir el error de estimación. Por otra parte, si alguna vez se extendiera la muestra de datos a 400 años, el cambio estructural sería tan grande que impediría creer que los retornos de hace cuatro siglos son útiles para predecir los retornos del próximo siglo. Por eso, siempre habrá poca evidencia sobre "el largo plazo".

Es sabido hace tiempo que si existen pocos datos, los parámetros de la distribución de retornos, es decir $P P R A_{t}$ y $\operatorname{VarACC}_{t}$, son más inciertos porque sufren de "riesgo muestral". Esto ya fue ilustrado en los Gráficos $\mathrm{N}^{\circ} 1$ y 2 . La incertidumbre muestral es de gran importancia para el inversionista. Es una fuente adicional de riesgo que impulsa al inversionista a reducir la fracción de su riqueza invertida en acciones (Knox 2002, Xia 2001). Luego, a mayor horizonte de inversión, mayor riego muestral y más riesgoso es apostar una determinada fracción de la cartera a las acciones.

Nicholas Barberis, profesor de la Universidad de Yale, usó simulaciones y la teoría de cómo combinar la incertidumbre muestral con la incertidumbre intrínseca de las acciones, para determinar la fracción óptima de la cartera destinada a acciones. También toma en cuenta el 
sesgo de muestra pequeña ${ }^{31}$. Su notable estudio fue publicado en el Journal of Finance (2000) y le mereció el Premio Paul Samuelson del año 2000. Termina dicho estudio afirmando que:

Estos resultados sugieren que los análisis de estrategias dinámicas que ignoran el riesgo de estimación, como los de Brennan et al. (1997) y los de Campbell y Viceira (1999), podrían requerir cautela para ser interpretados. Como no permiten al inversionista incorporar la incertidumbre de parámetros en su marco de decisiones, ellos pueden recomendar asignaciones demasiado altas a las acciones, y recomendar asignaciones accionarias demasiado sensibles a las variables que se usan para proyectar los retornos promedio. (Traducción y cursivas del autor.)

La importancia de esta crítica ha sido reconocida por Campbell y Viceira. En efecto, ellos analizan un caso muy simple donde hay incertidumbre muestral respecto de $P P R A_{t}$, no hay incertidumbre respecto del riesgo intrínseco DesvEstACC (toma el valor conocido $\left.\sigma_{\text {ACC }}\right)^{32}$, no hay sesgos de muestra pequeña y la renta fija está libre de riesgo. Encuentran que para maximizar la utilidad esperada del inversionista en ese caso simple, la ecuación (4) debe ser sustituida por la siguiente, para obtener la fracción de la cartera a destinar a acciones en forma óptima (2002, sección 5.5, p. 158):

$$
\alpha_{t}^{*}=P P R A_{t+1} \times \frac{1}{\operatorname{VarAcc}_{t}} \times\left(\frac{1}{\gamma}\right)-\left(\frac{-H_{g}}{\mathrm{H}}\right) \times \frac{\left(\text { EsDesvEstACC }_{t+1}\right)^{2}}{\operatorname{VarAcc}_{t}} \times\left(\frac{1}{\gamma}\right)
$$

donde el coeficiente $\left(-\mathrm{H}_{\mathrm{g}} / \mathrm{H}\right)$ es positivo por efecto de la incertidumbre muestral. La expresión EsDesvEstACC ${ }_{t+1}$ es la estimación del riesgo

${ }^{31}$ Las estimaciones empíricas de $P P R A_{t}$ y $\operatorname{VarACC}_{t}$ también sufren del sesgo de "muestra pequeña". Esto importa porque el sesgo de muestra pequeña para la fracción accionaria óptima $\alpha^{*}$, que se obtiene a partir de ellos, es mayor que la suma de los sesgos de muestra pequeña para $P P R A_{t}$ y $\operatorname{VarACC}_{t}$ (Okhrin y Schmid, 2006).

${ }^{32}$ Respecto al error de medición del riesgo intrínseco o volatilidad, algunos autores han confiado en el hallazgo de que este parámetro puede ser estimado con precisión aumentando la frecuencia temporal de los datos, dentro de un mismo horizonte físico de tiempo, para concluir que la volatilidad se estima sin error. Sin embargo, ese hallazgo no es válido cuando los datos son discretos en el tiempo, ni cuando los precios de las acciones exhiben saltos (Campbell y Viceira 2002, p. 155, nota 6). 
intrínseco de las acciones condicional a la muestra de datos disponible hasta $t$.

Lo importante es que el segundo término en (6) es negativo. Por lo tanto, reconocen que la incertidumbre muestral reduce la asignación óptima a acciones y contribuye a cancelar el efecto del autoseguro accionario.

Sin embargo, buena parte de la literatura reciente omite un ajuste como el contenido en la ecuación (6). Es el caso, por ejemplo, de Gomes, Kotlikoff y Viceira (2008), quienes proponen una cartera con $80 \%$ en acciones hasta los 40 años de edad ${ }^{33}$. También es el caso de Viceira (2009). Un motivo para esta omisión ha sido que calcular el nuevo término en (6) requiere cálculos difíciles. Sin embargo, eso no es excusa para ignorar que el riesgo muestral desautoriza recomendaciones tan extremas como tener el 80\% de la cartera en acciones.

Barberis (2000) ya demostró que el riesgo muestral puede alcanzar a una magnitud suficiente para cancelar el autoseguro accionario, que es la fuerza motriz de las recomendaciones de los trabajos recién citados. En general, las conclusiones de los trabajos que ignoran el riesgo muestral no son confiables.

\subsection{Crítica 2: el riesgo de predicción del PPRA aumenta con el horizonte}

El problema práctico planteado por la complejidad de la ecuación (6) fue resuelto de una manera efectiva por Lubos Pastor, profesor de la Escuela de Negocios de la Universidad de Chicago y Robert Stambaugh, profesor de Wharton, en un artículo publicado en febrero de 2009. Su método consiste en utilizar un sistema predictivo linearizado.

Se descompone la incertidumbre que enfrenta el inversionista en varios componentes:

${ }^{33}$ Ese resultado de Gomes et al. (2008) se explica por tres supuestos. Primero, omiten el riesgo muestral, que es mayor para plazos largos. Tienen sólo siete observaciones independientes de 20 años. Segundo, suponen que existe una pensión no contributiva que paga 68,8\% del ingreso laboral al jubilar, provista por el Estado sin riesgo político y cuyo monto presenta innovaciones sin correlación con el retorno accionario, ni siquiera en el largo plazo. Tercero, suponen que la correlación entre el retorno accionario y la innovación permanente en el ingreso laboral es nula a todos los plazos. Esto equivale a suponer que el crecimiento del país no afecta por igual a trabajadores y empresarios, lo cual contradice la evidencia de Benzoni et al. (2007). 
a) El riesgo intrínseco de las acciones a un año plazo (plazo corto). Éste es el único componente que no varía cuando crece el plazo de inversión.

b) La reducción de riesgo causada por el autoseguro accionario (natural hedge).

c) El riesgo muestral, ya señalado por Barberis (2000), originado en la disminución de observaciones independientes a medida que sube el plazo de inversión.

d) El riesgo originado en el hecho de que la ecuación predictiva basada en la razón dividendo a precio (ver la ecuación (5b)) predice el PPRA con error. Recordemos que apenas un período adelante el error de predicción de la ecuación (5b) es la friolera de 18,98\% anual.

e) Además, el error de predicción (d) se propaga hacia los períodos futuros. Los errores de predicción del PPRA de los períodos futuros se acumulan hasta un valor más grande cuando el horizonte de inversión es mayor.

Una cosa es aceptar la existencia del autoseguro accionario y otra es ignorar que el riesgo del inversionista tiene estos componentes adicionales cuya magnitud aumenta al crecer el horizonte de inversión. Más aún, Pastor y Stambaugh (2009) enfatizan que es lógicamente inconsistente aceptar la existencia del autoseguro accionario y suponer que no existe error de predicción en el premio por riesgo, porque sólo puede existir autoseguro si el PPRA varía en el tiempo, pero ello implica que el error de predicción de PPRA no puede ser nulo (como supusieron Campbell y Viceira, 1999).

El objetivo es determinar si el riesgo accionario total percibido por el inversionista, crece o decrece al aumentar el plazo de la inversión. Usando 206 años de datos para los Estados Unidos, ellos encuentran que la varianza anualizada del retorno accionario a 30 años plazo es ¡entre 20 y 50\% mayor! que la varianza del retorno de un solo año. A 10 años plazo el riesgo anualizado es $8 \%$ mayor a corto plazo (un año). En suma, la creciente incertidumbre sobre los parámetros y los errores de predicción más que compensan el aporte del autoseguro accionario a reducir el riesgo.

Estos autores no entregan el efecto de su dramático resultado sobre la fracción de la cartera invertida en acciones. Sin embargo, este resultado es exacto cuando la inversión alternativa es un bono de largo plazo indexado al IPC que rinde $0 \%$ anual sin riesgo de crédito. Consi- 
GRÁFICO N ${ }^{\circ}$ 6: EFECTO DEL HORIZONTE SOBRE CINCO COMPONENTES DEL RIESGO

PARA EL INVERSIONISTA (PASTOR Y STAMBAUGH, 2009)

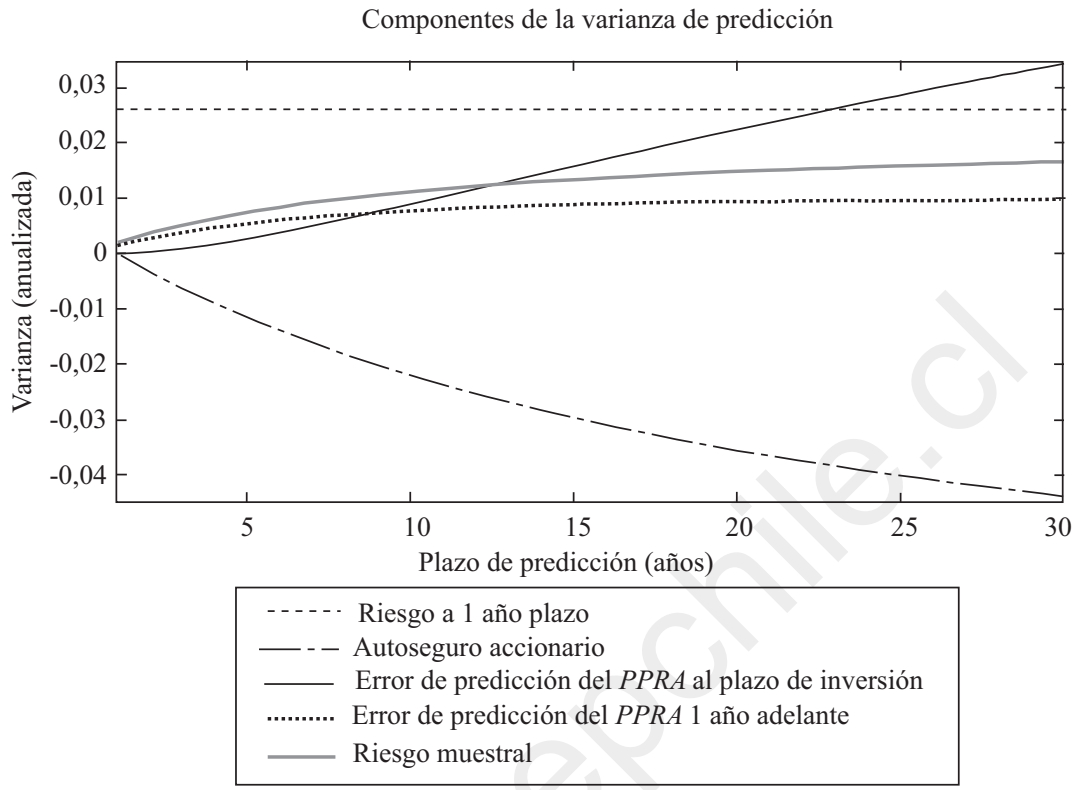

Fuente: Pastor y Stambaugh (2009), Figura 8, Panel B, p. 38.

derando la información provista en el Cuadro $\mathrm{N}^{\circ} 1$-los bonos soberanos de este tipo entregan retornos del orden de 2,0\% anual- y reconociendo que el riesgo de una cartera de estos bonos es muy inferior al riesgo de una cartera accionaria a cualquier plazo, se deduce que la fracción de la cartera que se recomienda invertir en acciones es mucho menor que la recomendada por Campbell, Chan y Viceira (2003).

\subsection{Otras críticas al sesgo pro-accionario}

La literatura reciente muestra más consideraciones que refuerzan la conclusión de que las acciones son aún más riesgosas de lo que indican las subsecciones anteriores. Sin embargo, las consideraciones resumidas aquí no tienen relación con el horizonte.

Primero, las variaciones en el tiempo del indicador de riesgo accionario también afectan la fracción invertida en acciones. La evidencia histórica para Estados Unidos muestra que la volatilidad o desvia- 
ción estándar del retorno accionario ha variado del simple al triple a lo largo de los años, sin contar los enormes vaivenes que registró durante la Gran Depresión 1930-1938, ni los que registró en 2008-2009. La literatura empírica de finanzas ha destinado amplios esfuerzos a predecir variaciones en la volatilidad, desarrollando los modelos GARCH. Se ha encontrado que la volatilidad revierte a una media de largo plazo.

También se ha encontrado que cuando el retorno accionario resulta malo, la volatilidad aumenta. Esto eleva el riesgo percibido por los inversionistas de invertir en acciones. Por esto, la teoría ha demostrado que al tomar en cuenta las variaciones en el tiempo del riesgo intrínseco, y las correlaciones mencionadas, es óptimo para el inversionista reducir la fracción invertida en acciones ${ }^{34}$. Este efecto tiende a reducir el porcentaje de la cartera dedicado a acciones, a cualquier plazo dado.

Segundo, la distribución empírica de los retornos accionarios exhibe mayor frecuencia para retornos extremos que lo supuesto por la distribución gaussiana. Esto significa que las acciones son más riesgosas, para cada plazo dado, que si la distribución fuera normal. Al analizar el caso del inversionista multiperíodo, se encuentra que este mayor riesgo se multiplica con el plazo de la inversión (Ortobelli, Huber y Schwartz, 2002).

Tercero, existe el riesgo de que el modelo predictivo que representa al autoseguro accionario esté equivocado ("incertidumbre de Knight”). En efecto, existe el riesgo de que los parámetros del pasado no se apliquen al futuro.

El riesgo de modelo genera una aversión adicional al riesgo, llamada aversión a la incertidumbre, que también reduce la proporción de la cartera de inversión que conviene destinar a las acciones a cualquier plazo dado. Maenhout (2004) muestra cómo modelar esta incertidumbre y cómo obtener la composición de cartera que maximiza la utilidad esperada del afiliado.

\subsection{El análisis de Wall Street en los últimos años}

A fines de los años 90, Ibbotson Associates (2000) propagaba en Wall Street el siguiente resultado: “En los 74 años entre 1926-1999 en Estados Unidos las acciones rentaron más que los bonos en 9,2\%

${ }^{34}$ La magnitud de la reducción oscila, siendo inversamente proporcional a la volatilidad prevista. Ver la ecuación (5.86) en Campbell y Viceira (2002), p. 150. 
real anual”. Suponiendo que este PPRA se repitiera en el futuro, y considerando que su magnitud fuese tan alta, parecía seguro que en la práctica una cartera accionaria dominaría a los bonos. La recomendación de inversión era evidente: maximizar la fracción accionaria.

Este capítulo muestra por qué esa inferencia es falsa. El 9,2\% real anual proviene de una muestra no representativa por ser muy corta. Un inversionista a 20 años plazo que desea 50 observaciones independientes requiere de 1.000 años de datos. En comparación, la precisión de una estimación basada en 74 años es demasiado baja.

En efecto, al año siguiente del término de esa muestra terminó el auge de las acciones "punto com" y la rentabilidad acumulada descendió significativamente. Ello volvió a ocurrir en 2008. Del mismo modo, la ampliación de la muestra a los 17 países con 106 años de datos permitió a Dimson, Marsh y Staunton (2006, Tabla $\mathrm{N}^{\circ}$ 4) determinar que la prima por riesgo accionario efectiva fue $4,1 \%$ anual en el período 1900-2005 en el conjunto de esos mercados, ponderándolos en forma simple y tomando la media geométrica en el tiempo, y usando como rentabilidad alternativa real a la que tuvieron los bonos de corto plazo nominales en Estados Unidos, que es 0,96\% anual.

Revisemos ahora la utilización de ese resultado pasado para proyectar el premio por riesgo accionario futuro, prospectivo para los próximos 20 años. Es posible que el enorme premio por riesgo accionario efectivo observado en 1926-1999 no haya sido producto de una burbuja, pero, aun así, que sea irrepetible. Suponga que la rentabilidad accionaria hasta 1999 se debió a algún motivo fundamental, por ejemplo a un aumento en la tolerancia al riesgo de los inversionistas, o a que las utilidades de las empresas fueron excepcionalmente altas, o a que se amplió el ámbito de diversificación de las inversiones a nivel internacional y nacional. Sin embargo, todos estos cambios pueden ocurrir sólo por una vez, y no pueden repetirse indefinidamente en el tiempo en la misma dirección.

Por ello, es incorrecto usar esa parte del retorno histórico (pasado) para predecir el retorno futuro de las acciones. Dimson et al. (2006) argumentan que de la prima por riesgo accionario histórica de 4,11\% anual para el período 1900-2005 en todo el mundo, la parte que no puede repetirse indefinidamente es $0,68 \%$ anual. Esto reduce la prima accionaria sostenible hasta 3,41\% anual (resta geométrica). 
Es natural agregar otro ajuste, justificado en que muchos países han emitido bonos de largo plazo indexados al IPC en los últimos diez años. La teoría ha establecido que para un inversionista a largo plazo, el activo libre de riesgo no es un bono nominal de corto plazo, sino un bono de largo plazo indexado al IPC (ver resumen en Campbell y Viceira 2002, cap. 3). El Cuadro $\mathrm{N}^{\circ} 1$ de este trabajo muestra que este último retorno ha sido cercano a 2,00\% anual en el mundo, cifra mayor que el 0,96\% usado por Dimson et al. (2006). Aplicando este nuevo retorno alternativo, el PPRA prospectivo queda en 2,36\% anual (resta geométrica). Esto es muy inferior al 9,2\% real anual de Ibbotson (2000), y recomienda asignar una fracción moderada de la cartera a acciones. Sin embargo, el margen de error de las estimaciones prospectivas es grande.

Algunos estudios muy recientes intentan proyectar el $P P R A$ condicionando al hecho de la crisis financiera de 2008-2009. Por ejemplo, el Banco Barclays sostiene que en el pasado, cada vez que la valorización de las acciones se contrajo después de un período de sobrevaloración, el premio por riesgo accionario efectivo resultó superior al $6 \%$ anual en los siguientes diez años ${ }^{35}$. Sin embargo, omite reconocer que esa afirmación está basada en un número muy pequeño de episodios pasados, tan pequeño que impide hacer inferencias confiables. Favero et al. (2009) calculan el intervalo de confianza al 95\% para su PPRA prospectivo a cinco años plazo, que es similar al de Barclays y toma en cuenta el efecto de los choques demográficos ya ocurridos y de sobrevaluaciones recientes. Encuentran que su amplitud es de ¡30 puntos porcentuales por año!

\section{Algunas lecciones para los multifondos}

Esta revisión de la literatura y los datos empíricos permiten rechazar la tesis de que un plazo de inversión largo justificaría, por ser largo, invertir una mayor proporción de la cartera en acciones. Lo correcto es que las acciones son más riesgosas que la renta fija, a todos los plazos. Revisamos a continuación algunas consecuencias para un sistema de pensiones de capitalización con gestión privada, 2010, p. 96.

${ }^{35}$ El estudio de Barclays es Equity Gilt 2010. Ver diario La Tercera, 7 de marzo 
como el chileno, que ofrece multifondos. Se recomienda también la revisión de Shiller (2005).

En las pensiones chilenas de capitalización, el tema del horizonte de inversión y las acciones incumbió solamente a los directorios de las AFP hasta 2001. Sin embargo, desde la creación del sistema de multifondos en septiembre de 2002, una parte de la responsabilidad de elegir cartera pasó a los afiliados — desde esa fecha pueden elegir multifondo- . Para decidir qué fondo escoger, algunos afiliados reúnen información de diversas fuentes, dentro de las cuales destacan la Superintendencia de Pensiones, las Administradoras de Fondos de Pensiones, los intermediarios financieros que ofrecen APV (Ahorro Previsional Voluntario) y algunos asesores previsionales.

Este estudio encuentra que la recomendación pro-accionaria y las falacias asociadas están más difundidas en Chile de lo que deberían. Afortunadamente la recomendación pro-accionaria está lejos de ser universal, pues varias AFP no la han suscrito, como puede verificarse revisando sus páginas web. Este estudio documenta que sólo dos de las cinco AFP acogieron la recomendación pro-accionaria en 2008-2009 (ver sección 3 y el Anexo), mientras que otras tres AFP se negaron a promoverla, demostrando una mayor actualización de su conocimiento financiero y una mayor prudencia.

En la reforma de 2001, otra parte de la responsabilidad pasó al Estado, pues la ley se atrevió a asignar a los afiliados que no eligen fondo —la mayoría - a un multifondo. El Estado asigna al fondo C, definido por un porcentaje accionario máximo de $40 \%$, a todos los afiliados mayores de 35 años que no eligen fondo ${ }^{36}$. A esa edad, la esperanza de vida es 39,8 años para hombres y 45 años para mujeres, y por lo tanto todos los afiliados tienen un horizonte de inversión muy largo. Por esto, la cartera del fondo C, con sólo $40 \%$ en acciones, es calificada de ineficiente por quienes promueven las carteras accionarias, cualquiera sea el argumento que utilicen. Este estudio demuestra que el Estado chileno hizo bien en no dar importancia a dichos reclamos ${ }^{37}$.

${ }^{36}$ Respecto al multifondo asignado a los mayores de 50/55 años (mujer/hombre), el contenido de esa ley sugiere que los legisladores decidieron esa norma por consideraciones no analizadas en este estudio, vinculadas al riesgo de que una renta vitalicia fija resulte cara al momento de pensionar.

${ }^{37}$ Este "final feliz" no implica que los legisladores chilenos hayan conocido la literatura y la evidencia resumida en este estudio, pues pueden haber decidido eso por otras razones. 
En realidad, este estudio sugiere reevaluar otra decisión del Estado chileno: asignar al multifondo $\mathrm{B}$, definido por un porcentaje accionario máximo de $60 \%$, a todos los afiliados menores de 35 años que no eligen fondo. Benzoni et al. (2007) presentan razones adicionales para dudar de la sabiduría de esa asignación.

Los directorios de las AFP tienen por su parte mucha responsabilidad en materia de riego accionario, aun después de la reforma de 2001. Por ejemplo, al interior de la cartera accionaria, ellos eligen si elevar o no la participación de los tipos más riesgosos de acciones. Por ello, la opinión de esos directorios es importante.

Los directorios de AFP también eligen si alejarse del centro del rango de porcentajes accionarios establecido por ley para cada tipo de multifondo, y en qué dirección hacerlo. Aquí la evidencia es clara: desde 2002 todas las AFP eligieron moverse hacia el máximo admisible y luego quedarse allí, incluso superándolo por períodos transitorios. Sin embargo, ese movimiento puede tener causas diferentes de la recomendación pro-accionaria evaluada en este estudio. Recordemos que tres de las cinco AFP no promovieron la recomendación pro-accionaria en 2008-2009, pero igual se movieron hacia el máximo admisible de acciones en cada tipo de multifondo. Parte de la literatura ha sugerido que podría originarse en la comparación frecuente con el desempeño financiero de los pares, posibilidad que no es materia de este estudio.

La reflexión final se refiere al nivel de riesgo apropiado para un sistema de seguridad social. La motivación del Estado para obligar al afiliado a ahorrar es asegurar un cierto nivel de vida en la vejez, proporcional a su nivel de vida en la fase de actividad, aunque el afiliado sea imprevisor. Este objetivo no es congruente con permitirle apostar una parte grande de sus ahorros obligatorios en títulos de alto riesgo de largo plazo, como son las acciones. Es inconsistente con otorgar al afiliado soberanía total en la asignación de su cartera de ahorros obligatorios. En efecto, si tuviera tal soberanía, no habría cómo negarle el derecho a invertir su ahorro obligatorio en otros multifondos hipotéticos que invertirían el 150\% o más de su patrimonio en acciones de alto riesgo, tal como propusieron Campbell, Chan y Viceira (2003). En cambio, si se acepta que esa soberanía es limitada, entonces no se justifica permitir a los afiliados invertir el 78\% del ahorro obligatorio de seguridad social en acciones, pues son de alto riesgo en el largo plazo. Los resultados de este estudio indican que el actual fondo 
A, que en Chile ha tenido 78\% en acciones desde 2004, es demasiado riesgoso en el largo plazo para ser compatible con la seguridad social. Ese nivel de riesgo sólo debería estar disponible para los ahorros voluntarios de largo plazo.

\section{ANEXO: LA FALACIA DE LA VARIANZA DEL PROMEDIO}

Las falacias "de horizonte largo" son aquellas que proponen que un plazo de inversión largo — diez años o más— reduciría drásticamente el riesgo de las carteras accionarias. Por ejemplo, una de esas falacias propone medir el riesgo con la probabilidad de que las acciones venzan a la renta fija (ver sección 2.4). Este Anexo está dedicado a la falacia más insidiosa, referida a la varianza del retorno promedio.

El indicador usado en finanzas para medir el impacto del horizonte sobre el riesgo es un cociente denominado "razón de varianzas"38. En el numerador está la varianza del valor final para inversiones a un plazo de $\mathrm{H}$ años, donde $\mathrm{H}$ es el horizonte o plazo. En el denominador está la varianza del valor final para inversiones a un año plazo, multiplicada por el plazo $\mathrm{H}$. Así, el valor de este cociente es la unidad cuando $\mathrm{H}=1$. Cuando el riesgo del inversionista crece al aumentar el horizonte, ello se refleja en que la razón de varianzas crece al aumentar $\mathrm{H}$. Si el riesgo es independiente del horizonte, ello se refleja en una razón de varianzas que se mantiene constante a pesar del aumento en $\mathrm{H}$.

Sin embargo, para que la razón de varianzas esté correctamente medida, es esencial que la varianza de las rentabilidades acumuladas se calcule primero, y que sólo sea dividida después por $\mathrm{H}$, el número de años. Invertir el orden de estas operaciones genera cifras gravemente distorsionadas, que inducen al observador incauto a creer que el riesgo cae cuando sube el horizonte, generando la falacia.

Un divulgador importante de esta distorsión fue J. Siegel, pues en sus libros ideó y reportó gráficos similares a los que mostramos a continuación (Siegel, 1998, figura 2.4 en p. 32). Otros divulgadores fueron Dimson et al. (2004) en sus gráficos No 1, 2 y 4.

Falacia: Cuando aumenta el horizonte de inversión, cae la variabilidad (o se estrecha el rango de valores probables) de la rentabilidad

${ }^{38}$ Hasta la fecha ningún intermediario financiero chileno ha reportado la "razón de varianzas” para alguna de las carteras de inversión que ofrece a los inversionistas. Tampoco la han reportado las autoridades. 
anual promedio. Esto demostraría que un horizonte mayor permite compensar los años de retornos buenos con los años de retornos malos.

Crítica: esta falacia confunde el riesgo del valor final para el inversionista (medido por variabilidad, o por rango de valores probables) con la precisión de la estimación de la rentabilidad promedio anual.

Todo promedio es más preciso (tiene menos incertidumbre muestral) cuando aumenta el número de valores promediados, es decir cuando aumenta el tamaño de la muestra. En cambio, toda suma es más imprecisa al aumentar el número de valores promediados. En nuestro caso, el error de estimación de la rentabilidad promedio cae cuando sube el horizonte, mientras que la variabilidad del valor final (una suma de retornos anuales) aumenta cuando sube el horizonte.

El Gráfico N 7 muestra cómo se comportan estas dos magnitudes en el caso de retornos sin autoseguro ${ }^{39}$. Una de ellas depende del tamaño de la muestra y la otra del horizonte o plazo de inversión.

GRÁFICO No 7: DOS VARIABILIDADES PARA EL CASO DE RETORNOS SIN AUTOSEGURO

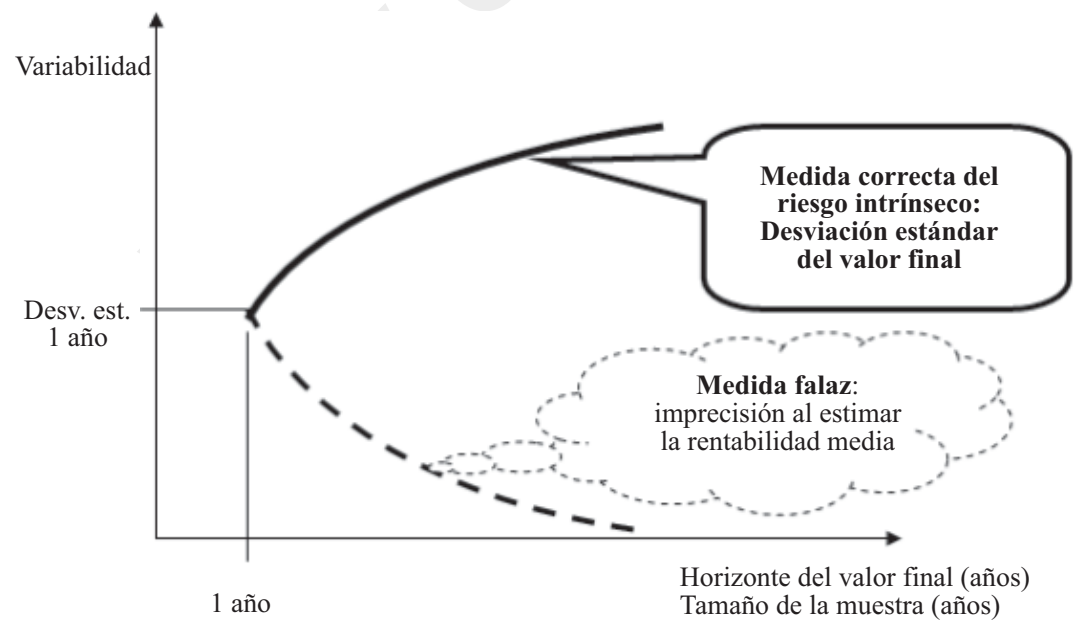

Fuente: Elaboración propia con las fórmulas $\sigma(\mathrm{VF})=\sigma_{\mathrm{i}} \mathrm{H}^{1 / 2} ; \sigma(\mathrm{r}$ de 1 año $)=\sigma_{\mathrm{i}} /\left(\mathrm{H}^{1 / 2}\right)$.

${ }^{39} \mathrm{El}$ caso sin autoseguro se denomina "retornos independientes e idénticamente distribuidos (i.i.d.)". 
Otra forma de expresar la diferencia es que aumentar el tamaño de una muestra no es lo mismo que aumentar el horizonte de inversión. Por el contrario, para una muestra histórica fija, esos dos aumentos son incompatibles, pues al aumentar el horizonte quedan menos observaciones independientes del retorno acumulado en esa muestra.

La falacia 1 es de gran actualidad para el afiliado chileno, como queda ilustrado en la página web de una AFP chilena grande, distinta de la citada en la sección 3. En su página se leía, el 17 de diciembre de 2008, lo siguiente:

Un fondo con más renta variable, como el Fondo A, tiene fluctuaciones más grandes de rentabilidad de un año a otro (en el corto plazo) en relación a un fondo con más renta fija. Sin embargo, en el largo plazo esta mayor fluctuación disminuye significativamente.

Los siguientes gráficos presentan el "rango de rentabilidad"40 esperado para el Fondo A y el Fondo E en 1, 10 y 20 años. La disminución en la variabilidad es mucho más significativa para el Fondo A. Esto significa que mientras mayor sea el plazo de inversión, más atractiva se hace la renta variable, en términos relativos, que la renta fija. Por lo tanto, los afiliados que cuentan con más tiempo antes de pensionarse, o los que quieren mantener su APV por largos periodos de tiempo, pueden enfrentar mejor el riesgo de los fondos con mayor inversión en Renta Variable. (Destacados con cursivas agregados por el autor.)

Así, esta AFP afirma que cuando el horizonte aumenta desde 1 a 20 años plazo, el riesgo del inversionista, que ella propone medir con el rango probable para las rentabilidades anualizadas baja desde $(32,2 \%-(-18,7 \%))=50,9$ puntos porcentuales a un año plazo, hasta $(12,4-(-1,0))=13,4$ puntos porcentuales en el multifondo A. Este fondo ha invertido cerca de $78 \%$ en acciones casi todo el tiempo desde 2004. Es decir, esta medida cae en 35,5 puntos porcentuales, y eso fue interpretado por esa AFP como una reducción de riesgo, y como causada por el aumento en el plazo de inversión.

El cálculo análogo para el multifondo E (sólo renta fija), cuando el horizonte va de 1 a 20 años plazo, entrega una caída en el rango de rentabilidad probable de sólo 10,72 puntos porcentuales.

${ }^{40} \mathrm{El}$ "rango de rentabilidad" es una medida de riesgo. Cumple el mismo rol de la varianza de la rentabilidad, con una leve transformación. 
GRÁFICO No 8: $\quad$ FIGURAS CLAVE EN LA PÁGINA WEB DE UNA AFP CHILENA GRANDE, FINES 2008

Rango de rentabilidad esperada del Fondo A para distintos plazos de inversión (*)

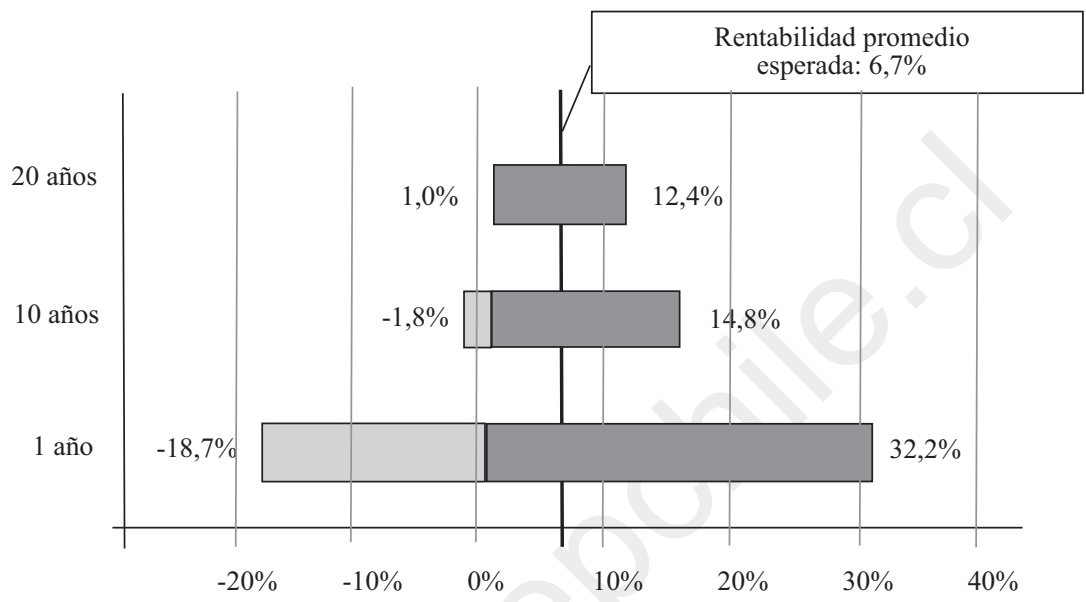

Rango de rentabilidad esperada del Fondo E para distintos plazos de inversión

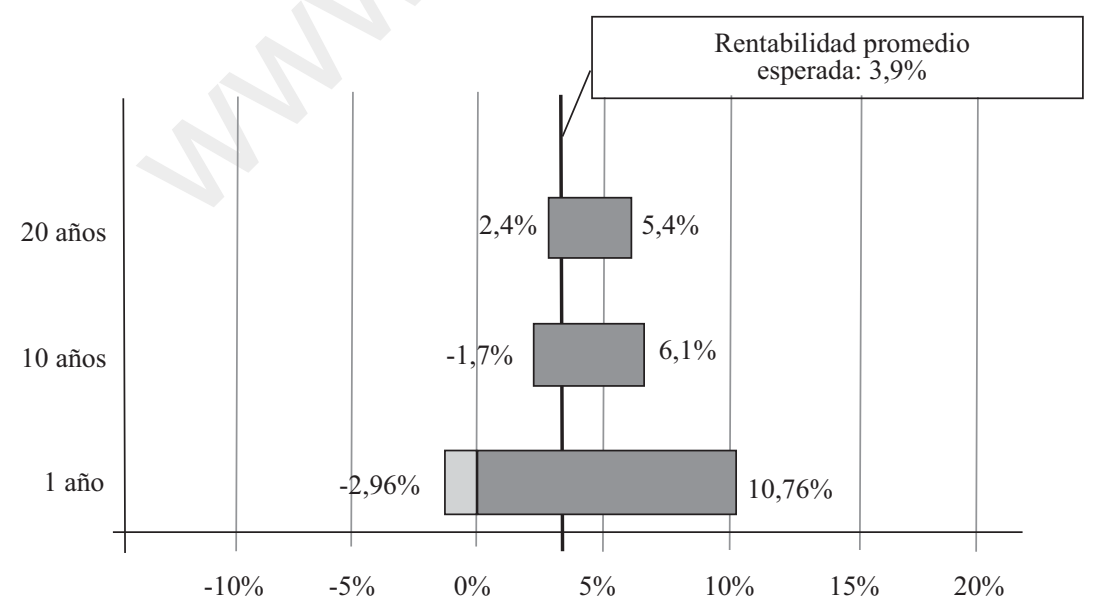

Fuente: Página web de una AFP chilena grande, 17 diciembre 2008. Disponible consultando al autor. 
Por último, esta AFP interpretaba que, como la caída de 35,5 puntos en el rango de rentabilidades del multifondo A es tres veces mayor que la caída de 10,72 puntos en el multifondo E, entonces el aumento de plazo reduciría más el riesgo de inversión en el fondo A que en el fondo E.

Llevada por la falacia de la varianza del promedio, esta AFP recomendaba elegir el multifondo A a los afiliados con horizonte de inversión de 20 años o más ${ }^{41}$.

\section{Origen de la falacia en más detalle}

Cuando se comparan los retornos de dos carteras, debe considerarse tanto el promedio como el riesgo de los retornos, entre los distintos escenarios posibles. Sin embargo, existe un tercer concepto: la precisión con que se mide el retorno promedio. En principio, esa precisión es independiente de la magnitud del riesgo de los retornos, pues son conceptos distintos.

Cuando se comparan distintos horizontes de inversión, los retornos difieren en dos dimensiones: en el tiempo (distintos años) y entre escenarios (distintos “estados de la naturaleza”). El peligro está en confundir la precisión de la rentabilidad promedio con la varianza promedio de la variabilidad acumulada.

$\mathrm{Al}$ anualizar el promedio de la rentabilidad acumulada se obtiene un promedio combinado de las dos dimensiones: se promedia entre escenarios, y también se promedia en el tiempo (entre años distintos). En el caso de la rentabilidad, estas operaciones exhiben la siguiente propiedad: no importa en qué orden se promedie. Es decir, el resultado es el mismo si se promedia primero la rentabilidad entre escenarios y después se divide por el número de períodos de tiempo, o si se procede en el orden inverso.

Sin embargo, en el caso de las medidas de riesgo no es válido intercambiar el orden de estas operaciones. Por ejemplo, en el caso gaussiano, el riesgo se mide con la varianza ${ }^{42}$. Ocurre que la varianza

${ }^{41}$ La Superintendencia de AFP no se opuso a la difusión de esta información por la AFP citada.

${ }^{42}$ Cuando la distribución de retornos tiene colas más gruesas que la gaussiana o "normal", la varianza no existe (es infinita) y es necesario usar otras medidas de variabilidad (Ortobelli, Huber y Schwartz, 2002). 
de las rentabilidades acumuladas, dividida después por el número de períodos de tiempo, entrega un resultado numérico distinto y mayor que dividir la rentabilidad acumulada de cada escenario por el número de períodos de tiempo y después obtener la varianza entre escenarios ${ }^{43}$. El orden no es intercambiable. Tampoco es intercambiable si el riesgo se mide con el rango de rentabilidad probable.

El motivo es que el segundo procedimiento introduce un efecto extra, originado en la ley de la estadística que establece que la precisión con que se estima un promedio a partir de una muestra es mayor cuando aumenta el número de elementos promediados. Por definición, el inverso de la precisión muestral es la varianza del retorno promedio. Si bien al aumentar el horizonte de inversión, la rentabilidad media será medida con mayor precisión, esa precisión no tiene interés para el inversionista. Al inversionista no le interesa la varianza del retorno promedio, sino la varianza del valor final de su inversión.

Por esto, la caída más veloz de la amplitud del rango de rentabilidades anualizadas en el fondo A que en el $\mathrm{E}$ no permite concluir que "mientras mayor sea el plazo de inversión, más atractiva se hace la renta variable”, como hizo esa AFP. Esa caída más veloz refleja otra cosa: que al aumentar el horizonte de inversión, la rentabilidad promedio es medida con mayor precisión en ambos fondos, y que el aumento de precisión es mayor para el fondo A. Eso no tiene relación con el riesgo del valor final, que es lo que interesa al inversionista.

\section{REFERENCIAS}

Barberis, N. (2000): "Investing for the Long Run When Returns Are Predictable". Journal of Finance, Vol. 55, No 1 (Feb.), pp. 225-264.

Benzoni, L., P. Collin-Dufresne y R. Goldstein (2007): "Portfolio Choice over the LifeCycle when the Stock and Labor Markets Are Cointegrated”, Journal of Finance, Vol. $62 \mathrm{~N}^{\circ}$ 5, p. 2123 y ss.

${ }^{43}$ La expresión matemática a continuación usa los símbolos $\mathrm{H}=\mathrm{n}^{\circ}$ de períodos de tiempo y $\mathrm{E}=\mathrm{n}^{\circ}$ de escenarios posibles. La expresión revela que el segundo procedimiento, en la derecha, difiere del procedimiento correcto, en la izquierda, porque el horizonte $\mathrm{H}$ aparece elevado al cuadrado. En efecto, el procedimiento de la derecha entrega un valor $H$ veces menor que el resultado de la izquierda.

$$
\frac{1}{H} \cdot\left(\frac{1}{E} \sum_{s=E}^{s=E}\left[R_{s}^{\text {acum }}-\text { promedio }_{s}\left(R_{s}^{\text {acum }}\right)\right]^{2}\right)>>\frac{1_{s=E}}{E_{s=E}}\left[\frac{1}{H}\left(R_{s}^{\text {acum }}-\operatorname{promedio}_{s}\left(R_{s}^{\text {acum }}\right)\right)\right]^{2}
$$


Campbell, J. y L. Viceira (1999): “Consumption and Portfolio Decisions When Expected Returns Are Time Varying”. Quarterly Journal of Economics, mayo 1999, Vol. 114, $\mathrm{N}^{\circ}$ 2, pp. 433-495.

(2002): Strategic Asset Allocation: Optimal Policies for Long-Term Investors. Oxford University Press.

Campbell, J., Y. L. Chan y L. Viceira (2003): “A Multivariate Model of Strategic Asset Allocation”. Journal of Financial Economics, Vol. 67 (1), pp. 41-80.

Cochrane, John (2008): “The Dog That Did Not Bark: A Defense of Return Predictability”. The Review of Financial Studies, Vol. 21 No 4, pp. 1533-1575.

Dimson, E., P. Marsh y M. Staunton (2002): Triumph of the Optimists. Princeton University Press.

(2004): “Irrational Optimism”. Financial Analysts Journal, January/February, Vol. 60, No 1: pp. 15-25.

(2006): “The Worldwide Equity Premium: A Smaller Puzzle”. Working paper London Business School, versión abril 7.

Favero, C., A. Gozluklu y A. Tamoni (2009): "Demographic Trends, the Dividend/Price Ratio and the Predictability of Long-Run Stock Market Returns”. Mimeo Bocconi University, diciembre.

Gomes, F., L. Kotlikoff y L. Viceira (2008): “Optimal Life-Cycle Investing with Flexible Labor Supply: A Welfare Analysis of Life-Cycle Funds”. NBER Working Paper 13966, Cambridge, MA.

Hoevenaars, R., R. Molenaar, P. C. Schotman y T. Steenkamp (2007): “Strategic Asset Allocation for Long Term Investors: Parameter Uncertainty and Prior Information”. Journal of Economic Dyanamics and Control. Vol. 32, № 9, septiembre 2008, pp. 2939-2970.

Ibbotson Associates (2000): Stocks, Bonds, Bills and Inflation Yearbook. Chicago, IL: Ibbotson Associates.

Jorion, P. (2003): “The Long-Term Risks of Global Stock Markets”. Financial Management, Vol. 32, № 4 (Winter), pp. 5-26, Blackwell.

Knox, T. (2002): "Learning How to Invest when Returns Are Uncertain”. 20 noviembre, Harvard University.

Maenhout, Pascal (2004): "Robust Portfolio Rules and Asset Pricing”. The Review of Financial Studies, Vol. 17, No 4 (invierno), pp. 951-983.

Merton, R. C. (1971): "Optimal Consumption and Portfolio Rules in a Continuous-Time Model”. Journal of Economic Theory, Vol. 3, pp. 373-413.

Okhrin, Y. y W. Schmid (2006): "Distributional Properties of Portfolio Weights". Journal of Econometrics, Vol. 134, № 1, pp. 235-256.

Ortobelli, S., I. Huber y E. Schwartz (2002): "Portfolio Selection with Stable Distributed Returns”. Mathematical Methods of Operations Research, Vol. 55, pp. 265-300.

Pastor, L. y R. Stambaugh (2008): "Predictive Systems: Living with Imperfect Predictors”. NBER Working Paper No 13804, febrero, www.nber.org. (2009): “Are Stocks Really Less Volatile in the Long Run?”. NBER Working Paper 14757, febrero, www.nber.org.

Samuelson, P. A. (1979): "Why We Should Not Make Mean Log of Wealth Big Though Years to Act Are Long”. Journal of Banking and Finance, 3, pp. 305-307.

Shiller, Robert (2000, 2005): Irrational Exuberance. Princeton University Press. (2005): "The Life-Cycle Personal Accounts Proposal for Social Security: An Evaluation”. NBER Working Paper 11300, http://www.nber.org/papers/w11300. 
Siegel, Jeremy (1998): Stocks for the Long Run. New York: McGraw-Hill, segunda edición.

Viceira, Luis M. (2009): “Pension Fund Design in Developing Economies”. Presentación en II Congreso Internacional Fiap - Asofondos, Cartagena de Indias, Colombia, abril 23-24.

Willen, P. y F. Kubler (2006): “Collateralized Borrowing and Life Cycle Portfolio Choice”. Public Policy Discussion Papers N ${ }^{\circ}$ 06-4, Federal Reserve Bank of Boston.

Xia, Yihong (2001): "Learning about Predictability: The Effects of Parameter Uncertainty on Dynamic asset Allocation”. Journal of Finance, 56, p. 205-246. 